Article

\title{
Bioactive Compounds in Aegopodium podagraria Leaf Extracts and Their Effects against Fluoride-Modulated Oxidative Stress in the THP-1 Cell Line
}

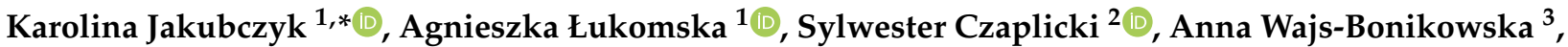 \\ Izabela Gutowska ${ }^{4}$, Norbert Czapla ${ }^{5}$, Małgorzata Tańska ${ }^{2} \mathbb{D}$ and Katarzyna Janda-Milczarek ${ }^{1}$ (D)
}

1 Department of Human Nutrition and Metabolomics, Pomeranian Medical University in Szczecin, ul. Broniewskiego 24, 71-460 Szczecin, Poland; agnieszka_lukomska@wp.pl (A.Ł.); katarzyna.janda.milczarek@pum.edu.pl (K.J.-M.)

2 Department of Plant Food Chemistry and Processing, Faculty of Food Sciences, University of Warmia and Mazury in Olsztyn, Pl. Cieszyński 1, 10-726 Olsztyn, Poland; sylwester.czaplicki@uwm.edu.pl (S.C.); m.tanska@uwm.edu.pl (M.T.)

3 Institute of Natural Products and Cosmetics, Faculty of Biotechnology and Food Sciences, Lodz University of Technology, Stefanowskiego 2/22, 90-537 Lodz, Poland; anna.wajs@p.lodz.pl

4 Department of Medical Chemistry, Pomeranian Medical University in Szczecin, ul. Powstancow Wlkp 72, 71-460 Szczecin, Poland; gutowska@pum.edu.pl

check for updates

Citation: Jakubczyk, K.; Łukomska, A.; Czaplicki, S.; Wajs-Bonikowska, A.; Gutowska, I.; Czapla, N.; Tańska, M.; Janda-Milczarek, K. Bioactive Compounds in Aegopodium podagraria Leaf Extracts and Their Effects against Fluoride-Modulated Oxidative Stress in the THP-1 Cell Line. Pharmaceuticals 2021, 14, 1334. https://doi.org/10.3390/ph14121334

Academic Editors:

Sabesan Yoganathan and Ilkay Erdogan Orhan

Received: 12 November 2021 Accepted: 14 December 2021 Published: 20 December 2021

Publisher's Note: MDPI stays neutral with regard to jurisdictional claims in published maps and institutional affiliations.

Copyright: (c) 2021 by the authors. Licensee MDPI, Basel, Switzerland. This article is an open access article distributed under the terms and conditions of the Creative Commons Attribution (CC BY) license (https:// creativecommons.org/licenses/by/ $4.0 /)$.
5 Clinic of Plastic, Endocrine and General Surgery, Pomeranian Medical University in Szczecin, 72-009 Police, Poland; norbertczapla@gmail.com

* Correspondence: karolina.jakubczyk@pum.edu.pl; Tel.: +489-144-148-11

\begin{abstract}
Aegopodium podagraria L. (goutweed), a member of the Apiaceae family, is a common perennial plant found all around the world that has been used in folk medicine since antiquity. Goutweed leaves contain polyacetylenes, essential oils, mono- and sesquiterpenes, vitamins, macro- and microelements, and phenolic compounds. In spite of its many health-promoting properties, including antioxidant effects, the plant has not been thoroughly studied. The aim of this study was to investigate the antioxidant properties of different goutweed leaf extracts and their effects on the THP-1 cell line, and also to describe the chemical characteristics of goutweed. Falcarinol and falcarindiol and essential oil were determined by gas chromatography coupled with mass spectrometry. Spectrophotometry was used to measure the total content of polyphenols and antioxidant activity-by DPPH and FRAP methods. Oxidative stress in THP-1 cells was induced via sodium fluoride. Then, goutweed leaf extracts were added to evaluate their influence on antioxidant potential (ABTS) and the activity of antioxidant enzymes. Confocal microscopy was used to visualise the production of cytoplasmic and mitochondrial reactive oxygen species (ROS) and for in vitro imaging of apoptosis. The ethanol extracts have a high total content of polyphenols, polyacetylenes, and essential oil, as well as high antioxidant potential. The main volatiles represented diverse chemical groups, which are both oxygenated derivatives of sesquiterpenes and monoterpenes. We also demonstrated positive effects of the high antioxidant potential and increased activity of antioxidant enzymes on cell cultures under severe fluoride-induced oxidative stress. Extraction at $80{ }^{\circ} \mathrm{C}$ and the use of ethanol as a solvent increased the antioxidant capacity of the extract. The leaves of Aegopodium podagraria may serve as a valuable source of antioxidants in the daily diet and assist in the prevention and treatment of oxidative stress-mediated conditions, e.g., inflammatory conditions, cardiovascular diseases, neurodegenerative diseases, and even obesity.
\end{abstract}

Keywords: natural compounds; antioxidant; oxidative stress; goutweed; fluoride; polyphenols

\section{Introduction}

Common goutweed (Aegopodium podagraria L.), a member of the Apiaceae family, is a common perennial plant found all around the world, including Europe, North America, 
and Asia [1,2]. It spreads readily via creeping rhizomes and stolons, as well as being frost hardy. Goutweed is also highly competitive against other species, rapidly taking over the land, which makes it easy to source. Goutweed leaves have been used in folk medicine since antiquity. Infusions made from dried leaves are recommended to remedy gout, haemorrhoids, inflammatory conditions of the kidneys and bladder, as an auxiliary treatment for kidney stone disease, and to improve metabolism. Fresh leaves can be put on wounds to facilitate healing [1-3]. Apart from its medicinal properties, goutweed is also an edible plant. New leaves were traditionally eaten in the spring and put into soups, often together with other plants. In many countries, leaves are used in the form of infusions, extracts, and supplements. Goutweed leaves contain polyacetylenes, including falcarinol and falcarindiol, essential oils, chiefly mono- and sesquiterpenes, vitamins, as well as macro- and microelements, notably iron, copper, manganese, titanium, boron, calcium and potassium [3-5]. Phenolic compounds, including coumarins, phenolic acids, and flavonoids, can also be found in goutweed [1-5]. Falcarinol and falcarindiol are the main biologically active compounds naturally occurring in plants of the Apiaceae family, both wild, e.g., goutweed, and in vegetables such as carrots, parsley, and celery. The amount of these compounds depends on many factors, including the species and part of the plant. They belong to the class of organic compounds known as long-chain fatty alcohols. Falcarinol is a polyyne with two carbon-carbon triple bonds and two double bonds (Figure 1). By influencing prostaglandin metabolism, falcarinol has anti-inflammatory and anticoagulant properties. Its concentration-dependent antioxidant properties have also been demonstrated $[6,7]$.

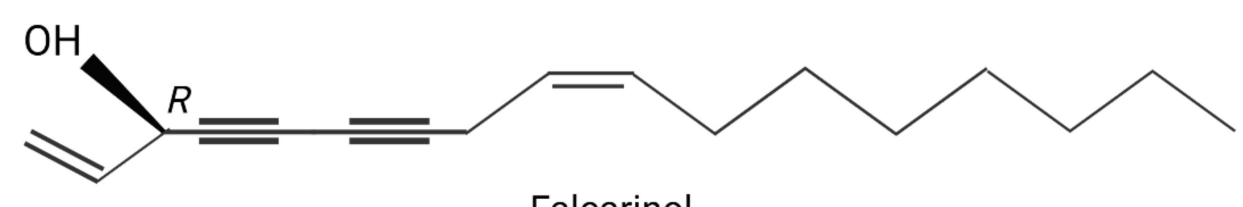

Falcarinol

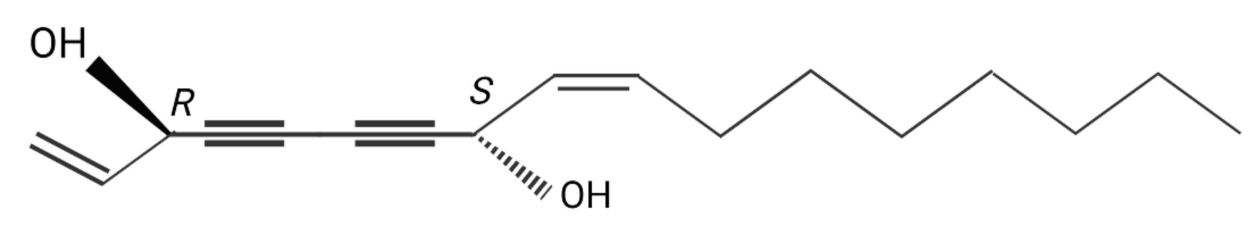

\section{Falcarindiol}

Figure 1. Chemical structures of the polyacetylenes falcarinol [(3R)-heptadeca-1,9(Z)-diene-4,6diyne-3-ol] and falcarindiol [(3R,8S)-heptadeca-1,9(Z)-diene-4,6-diyne-3,8-diol]. Created with BioRender.com.

According to the available literature, Aegopodium podagraria is safe to use [1-3]. This is because of the wide margin between the therapeutic and toxic dose of the main active compound in the plant (falcarinol), which makes it possible to use the product without the risk of adverse effects [4]. On the other hand, there is a shortage of scientific reports confirming the safety of extracts in vitro and in vivo, as well as detailed biochemical analyses of goutweed preparations and their health benefits.

That is why the aim of this study was to investigate the antioxidant properties of different goutweed leaf extracts and their effects on the THP-1 cell line and also to describe goutweed characteristics in terms of the content of essential oils, total polyphenols, and polyacetylenes-the main active compounds found in the plant. Additionally, we examined the effects of solvent DMSO (dimethylsulfoxide) at a concentration of $1 \%$ the volume of the cell medium, comparing it to standard solvents, that is water and ethanol, and studied the effects of extracts against sodium fluoride toxicity in the THP-1 cell line. The monocytes 
of the THP-1 cell line easily differentiate into macrophages after treatment with phorbol ester, and the process itself is fast and takes only $24 \mathrm{~h}$. Macrophages are a major source of reactive oxygen species, reactive nitrogen species, and peroxynitrite generated through the so-called respiratory burst. Constitutively released pro-inflammatory cytokine, e.g., tumour necrosis factor- $\alpha$, triggers nuclear factor- $\mathrm{kB}$ and activator protein- 1 translocation, leading to the overproduction of reactive oxygen species and reactive nitrogen species in macrophages. Additionally, tissue-resident macrophages present in the liver, lung, skin, kidney, bone, and connective tissue act as non-specific killer cells that eliminate bacteria, foreign bodies, dead cells, and debris and recruit monocytes/macrophages in response to inflammatory signals. The activation of transcription factors in the long-lived tissue-resident macrophages and/or monocyte-derived macrophages triggers epigenetic modifications, leading to the pathogenesis of chronic diseases. Therefore, the application of an in vitro model using macrophages has been increasingly used to study the antioxidant properties of nutraceuticals. In addition, it makes it possible to take into account the key biological parameters needed to reflect real physiological conditions [8].

\section{Results}

\subsection{Antioxidant Capacity of Goutweed Extracts Obtained Using Different Solvents}

The antioxidant potential of the extracts at $100 \mathrm{mg} / \mathrm{L}$ ranged from $6.54 \%$ to $15.65 \%$. The highest percentage inhibition of DPPH (2,2-diphenyl-1-picrylhydrazyl) $(15.65 \%)$ was observed in the extract dissolved in DMSO, which was extracted with water at $90{ }^{\circ} \mathrm{C}$. The lowest inhibition potential was noted with the first extraction method, amounting to $13 \%$ for DMSO and $6.6 \%$ for water/ethanol. The percentage difference between solvents used in the same extraction method amounted to $41.9 \%, 40.3 \%, 56 \%$, and $32.3 \%$, respectively. The results and $\mathrm{p}$-values are presented in Table 1.

Table 1. Antioxidant potential (DPPH, FRAP); total polyphenol content (TPC) in Aegopodium podagraria leaf extracts $(100 \mathrm{mg} / \mathrm{L})$.

\begin{tabular}{|c|c|c|c|c|c|c|c|c|c|c|}
\hline \multirow{3}{*}{$\begin{array}{c}\text { Extraction } \\
\text { water } 25^{\circ} \mathrm{C}^{\mathrm{z}}\end{array}$} & \multirow{3}{*}{$\begin{array}{l}\text { Solvent } \\
\text { water }\end{array}$} & \multicolumn{3}{|c|}{ DPPH } & \multicolumn{3}{|c|}{ FRAP } & \multicolumn{3}{|c|}{ TPC } \\
\hline & & \multicolumn{3}{|r|}{$[\%]$} & \multicolumn{3}{|c|}{$[\mathrm{uM} \mathrm{Fe}(\mathrm{II}) / \mathrm{L}]$} & \multicolumn{3}{|c|}{$\begin{array}{l}\text { [mg/L] Gallic Acid } \\
\text { (GAE)/[g/100 g DW] }\end{array}$} \\
\hline & & 9.65 & \pm & $1.29 * \mathrm{y}, \mathrm{x}, \mathrm{v}, \mathrm{f}, \mathrm{h}$ & 177.79 & \pm & $32.31 * \mathrm{y}, \mathrm{x}, \mathrm{w}$ & 5.66 & \pm & $0.45 * \mathrm{y}, \mathrm{x}, \mathrm{w}, \mathrm{v}, \mathrm{f}, \mathrm{h}$ \\
\hline water $90^{\circ} \mathrm{C}^{\mathrm{y}}$ & water & 6.54 & \pm & $0.96 * z, x, w, v, u, h, f$ & 331.03 & \pm & $46.45 * z$ & 12.85 & \pm & $0.22 * \mathrm{z}, \mathrm{w}, \mathrm{u}$ \\
\hline ethanol $25^{\circ} \mathrm{C}^{\mathrm{x}}$ & ethanol & 13.92 & \pm & $1.07 * \mathrm{z}, \mathrm{y}, \mathrm{w}, \mathrm{u}, \mathrm{f}$ & 333.55 & \pm & $123.55 * z$ & 13.73 & \pm & $0.38 * \mathrm{z}, \mathrm{u}$ \\
\hline ethanol $80^{\circ} \mathrm{C}^{\mathrm{w}}$ & ethanol & 10.83 & \pm & $1.40 * \mathrm{y}, \mathrm{x}, \mathrm{v}, \mathrm{f}, \mathrm{h}$ & 416.42 & \pm & $36.85 * \mathrm{z}, \mathrm{v}, \mathrm{u}, \mathrm{f}, \mathrm{h}$ & 17.79 & \pm & $1.02 * z, y, u, h$ \\
\hline water $25^{\circ} \mathrm{C}^{\mathrm{v}}$ & DMSO & 9.71 & \pm & $0.36 * z, y, w, u$ & 151.98 & \pm & $14.50 * \mathrm{~W}$ & 4.98 & \pm & $0.46^{* \mathrm{z}, \mathrm{u}}$ \\
\hline water $90^{\circ} \mathrm{C}^{\mathrm{u}}$ & DMSO & 15.11 & \pm & $0.46 * \mathrm{y}, \mathrm{w}, \mathrm{v}, \mathrm{f}, \mathrm{h}$ & 259.68 & \pm & $14.22 * \mathrm{~W}$ & 11.03 & \pm & $0.49 * \mathrm{y}, \mathrm{x}, \mathrm{w}, \mathrm{u}, \mathrm{f}, \mathrm{h}$ \\
\hline ethanol $25^{\circ} \mathrm{C}^{\mathrm{f}}$ & DMSO & 14.42 & \pm & $2.10 * \mathrm{z}, \mathrm{y}, \mathrm{x}, \mathrm{w}, \mathrm{u}$ & 293.91 & \pm & $96.06 * \mathrm{~W}$ & 13.83 & \pm & $3.81^{* z, u}$ \\
\hline ethanol $80^{\circ} \mathrm{C}^{\mathrm{h}}$ & DMSO & 15.65 & \pm & $0.55 * \mathrm{z}, \mathrm{y}, \mathrm{w}, \mathrm{u}$ & 302.86 & \pm & $44.66 * \mathrm{w}$ & 13.96 & \pm & $0.23 * \mathrm{z}, \mathrm{w}, \mathrm{u}$ \\
\hline
\end{tabular}

${ }^{*}$ FDR $p \leq 0.05$ between type of extract, $p \leq 0.05$ between type of extract: $\mathrm{z}$-water $25{ }^{\circ} \mathrm{C}$, solvent-water; $\mathrm{y}-\mathrm{water} 90{ }^{\circ} \mathrm{C}$, solvent-water; x-ethanol $25{ }^{\circ} \mathrm{C}$, solvent-water; w-ethanol $80^{\circ} \mathrm{C}$, solvent-water; v-water $25^{\circ} \mathrm{C}$, solvent-DMSO; u-water $90^{\circ} \mathrm{C}$, solvent-DMSO; f-ethanol $25^{\circ} \mathrm{C}$, solvent-DMSO; h-ethanol $80^{\circ} \mathrm{C}$, solvent-DMSO; DW-dry weight.

The lowest reducing power, determined using the FRAP (ferric-reducing antioxidant power) assay in leaf extracts was found in the first extract for both solvents. In the extract dissolved in water, the result was $177.8 \mu \mathrm{M} \mathrm{Fe}(\mathrm{II}) / \mathrm{L}$, whereas for DMSO, it was $152 \mu \mathrm{M}$ $\mathrm{Fe}(\mathrm{II}) / \mathrm{L}$. Percentage-wise, the difference amounted to $14.5 \%$ and was not statistically significant $(p>0.05)$ (Table 1$)$. The greatest amount of Fe(II) ions was observed in samples extracted with ethanol at $80{ }^{\circ} \mathrm{C}$ (water: $416.4 \mu \mathrm{M}$ Fe(II)/L; DMSO: $302.9 \mu \mathrm{M} \mathrm{Fe}(\mathrm{II}) / \mathrm{L}$ ). Percentage-wise, the difference amounted $27.3 \%$ and was not statistically significant, either $(p>0.05)$. In the second extract, the difference amounted to $21.6 \%$, and in the third, it amounted to $12 \%$. The remaining p-values are presented in Table 1.

The highest concentration of polyphenolic compounds in leaf extracts was noted in the fourth extract for both solvents. For the extract dissolved in ethanol, the content was 
$17.8 \mathrm{mg} / \mathrm{L}$, and for DMSO, it was $14.0 \mathrm{mg} / \mathrm{L}$. Percentage-wise, the difference amounted to $21.5 \%$ and was statistically significant $(p \leq 0.05)$ (Table 1$)$. The lowest concentration of phenolic compounds was observed in the first extract, which was made with water at room temperature (water: $5.7 \mathrm{mg} / \mathrm{L}$, DMSO: $5 \mathrm{mg} / \mathrm{L}$ ). Percentage-wise, the difference amounted to $12.0 \%$ and was statistically significant, too $(p \leq 0.05)$. In the second extract, the difference amounted to $14.1 \%$, and in the fluoride third, it was as little as $1 \%$. The total polyphenols content (TPC) based on the dry weight of the extract was $17.79 \mathrm{~g} / 100 \mathrm{~g}$ for the $80^{\circ} \mathrm{C}$ ethanol extract, which was dissolved in ethanol $(17.79 \mathrm{mg} / \mathrm{L})$. Thus, the percentage of polyphenols in the extract is a maximum of $17.79 \%$. The results and p-values are presented in Table 1.

\subsection{Chemical Composition of the Leaf Extracts (Polyacetylene and Essential Oil)}

Goutweed leaf extracts chosen for the in vitro analysis were also tested for the content of polyacetylenes: falcarinol and falcarindiol. Significantly higher levels of both compounds were found in the extracts made at $80^{\circ} \mathrm{C}$, and falcarinol was absent in extracts made at lower temperatures $(p \leq 0.05)$ (Table 2).

Table 2. Polyacetylene content in Aegopodium podagraria leaf extracts (100 mg/L).

\begin{tabular}{lcc}
\hline Extract & Falcarinol $\mathbf{~ m g / 1 0 0 g}$ & Falcarindiol $\mathbf{~ m g / 1 0 0 g}$ \\
\hline ethanol $25^{\circ} \mathrm{C}^{\mathrm{f}}$ & nd & $185.81 \pm 19.21^{* \mathrm{~h}}$ \\
ethanol $80^{\circ} \mathrm{C}^{\mathrm{h}}$ & $46.91 \pm 3.47^{* \mathrm{f}}$ & $474.51 \pm 75.74 * \mathrm{f}$ \\
\hline
\end{tabular}

*FDR $p \leq 0.05$ between type of extract: $\mathrm{f}$-ethanol $25^{\circ} \mathrm{C}$; h-ethanol $80^{\circ} \mathrm{C}$.

In order to characterise the volatile compounds present in freeze-dried leaves, an essential oil was isolated, and its chemical composition was determined. With the use of the GC-FID-MS method, a total of 106 compounds, accounting for more than $87 \%$ of the whole oil, were identified in the essential oil of the leaves of Aegopodium podagraria.

The $A$. podagraria oil was found to contain many different compounds. The main volatiles represented diverse chemical groups, both oxygenated derivatives of sesquiterpenes ( $\beta$-caryophyllene epoxide (3.6\%), humulene epoxide II $(3.5 \%)$, khusinol $(2.0 \%)$, ledene oxide II (1.8\%), salvial-4(14)-en-1-one $(1.8 \%))$ and monoterpenes ( $\beta$-pinene $(3 \%)$, $m$-cymene $(1.4 \%))$ as well as oxygenated derivatives of monoterpenes such as linalool $(1.8 \%)$ and hydrogenated sesquiterpenes ( $\beta$-bisabolene $(1.8 \%), \beta$-elemene $(1.6 \%))$. The essential oil also contained many oxygen derivatives of chain alkanes, predominantly: octanal $(4.1 \%)$ and heptadecan-2-one (2.4\%). Several fatty acids were detected in A. podagraria, the main one being palmitic acid (2.3\%) (Table 3$)$.

Table 3. Composition of the essential oil of freeze-dried leaves of Aegopodium podagraria.

\begin{tabular}{ccc}
\hline Compound & Amount [\%] & RI exp. ${ }^{*}$ \\
\hline n-Hexanal & 0.4 & 772 \\
$n$-Heptanal & 1.1 & 876 \\
Benzaldehyde $+\alpha$-Pinene & 0.4 & 927 \\
Octane-2,3-dione & 0.1 & 959 \\
6-Methylhept-5-ene-2-one & 0.8 & 961 \\
$\beta$-Pinene & 3.0 & 967 \\
2-Pentylfuran & 0.5 & 976 \\
n-Octanal & $\mathbf{4 . 1}$ & 980 \\
2-Phenylethanal & 0.2 & 1006 \\
m-Cymene & $\mathbf{1 . 4}$ & 1010 \\
Limonene & 0.4 & 1019 \\
(E)-Ocimene & 0.1 & 1025 \\
(E)-Oct-2-enal & 0.2 & 1031 \\
(-Terpinen & 0.1 & 1043 \\
3-Ethyl-2-methylhexa-1,3-diene & 0.4 & 1048 \\
\hline
\end{tabular}


Table 3. Cont

\begin{tabular}{|c|c|c|}
\hline Compound & Amount [\%] & RI exp. * \\
\hline cis-Linalol oxide (furanoid) & 0.2 & 1057 \\
\hline$(E, E)$-Octa-3,5-dien-2-one & 0.3 & 1065 \\
\hline Nonan-2-one & 1.1 & 1070 \\
\hline$n$-Heptanoic acid & 0.1 & 1075 \\
\hline (E)-6-Methylhepta-3,5-dien-2-one & 0.1 & 1078 \\
\hline$n$-Nonanal & 0.8 & 1082 \\
\hline Linalool & 1.8 & 1085 \\
\hline Nopinone & 0.4 & 1106 \\
\hline Non-3-en-2-one & 0.1 & 1116 \\
\hline trans-Pinocarveol & 0.9 & 1123 \\
\hline$(E, Z)-N o n a-2,6$-dienal & 0.1 & 1126 \\
\hline cis-Verbenol & 0.3 & 1128 \\
\hline (E)-Non-2-en-1-al & 0.5 & 1135 \\
\hline$\alpha$-Pinocarvone & 0.3 & 1138 \\
\hline trans-Verbenol & 0.1 & 1146 \\
\hline endo Borneol & 0.2 & 1149 \\
\hline p-Cymen-8-ol & 0.3 & 1160 \\
\hline Terpinen-4-ol & 0.8 & 1162 \\
\hline Myrtenal & 0.3 & 1169 \\
\hline$\alpha$-Terpineol & 0.4 & 1172 \\
\hline Myrtenol & 0.8 & 1179 \\
\hline Caprylicacid & 1.2 & 1184 \\
\hline 2,6,6-Trimethylcyclohex-1-ene-1-carbaldehyde & 0.1 & 1194 \\
\hline trans-Carveol & 0.1 & 1196 \\
\hline Thymol methylether & 0.1 & 1209 \\
\hline p-Cumical dehyde & 0.1 & 1211 \\
\hline (Z)-Hex-3-enyl isovalerate & 0.1 & 1218 \\
\hline Geraniol & 0.2 & 1236 \\
\hline (E)-Dec-2-en-1-al & 1.0 & 1238 \\
\hline$p$-Menth-4(8)-en-9-ol & 0.1 & 1249 \\
\hline Pelargonic acid & 0.9 & 1268 \\
\hline Carvacrol & 0.5 & 1277 \\
\hline Dihydroedulan I & 1.3 & 1282 \\
\hline Dihydroedulan II & 1.2 & 1286 \\
\hline$(E, E)$-Deca-2,4-dienal & 0.1 & 1289 \\
\hline Tridecane & 0.7 & 1300 \\
\hline$\alpha$-Cubebene & 0.1 & 1349 \\
\hline Non-2-enoic acid & 0.6 & 1353 \\
\hline Capric acid & 0.5 & 1365 \\
\hline$\alpha$-Cubebene & 0.2 & 1373 \\
\hline$\alpha$-Ylangene & 0.2 & 1377 \\
\hline$\beta$-Elemene & 1.6 & 1389 \\
\hline$(E)$-Dec-2-enoic acid & 0.3 & 1397 \\
\hline$(E)$ - $\alpha$-Ionone & 0.1 & 1407 \\
\hline (E- $\beta$-Caryophyllene & 0.7 & 1419 \\
\hline$\beta$-copaene & 0.3 & 1429 \\
\hline trans- $\alpha$-Bergamotene & 0.4 & 1434 \\
\hline (Z)- $\beta$-Farnesene & 0.3 & 1437 \\
\hline$(E)-\beta$-Farnesene & 0.4 & 1447 \\
\hline$\alpha$-Himachalene & 0.2 & 1450 \\
\hline$\alpha$-Humulene & 0.4 & 1453 \\
\hline 5,6-Epoxy- $\beta$-ionone & 0.7 & 1463 \\
\hline$\beta$-Ionone & 1.0 & 1466 \\
\hline$\alpha$-Curcumene $+\gamma$-Muurolene & 0.5 & 1472 \\
\hline Germacrene D & 1.0 & 1479 \\
\hline$(3 Z, 6 E)-\alpha$-Farnesene & 0.3 & 1482 \\
\hline$\alpha$-Selinene & 0.3 & 1484 \\
\hline
\end{tabular}


Table 3. Cont.

\begin{tabular}{|c|c|c|}
\hline Compound & Amount [\%] & RI exp. * \\
\hline$\gamma$-Muurolene & 0.2 & 1490 \\
\hline 2,4-Ditert-butylphenol & 1.3 & 1493 \\
\hline$\beta$-Bisabolene & 1.8 & 1503 \\
\hline$\gamma$-Cadinene & 0.2 & 1508 \\
\hline$\delta$-Cadinene & 0.7 & 1516 \\
\hline$\alpha$-Calacorene & 0.4 & 1531 \\
\hline Isoaromadendreneepoxide & 1.1 & 1545 \\
\hline cis-Sesquisabinenhydrate & 0.2 & 1553 \\
\hline 1,5-Epoxysalvial-4(14)-ene & 0.4 & 1559 \\
\hline Spathulenol & 15.8 & 1576 \\
\hline$\beta$-Caryophylleneepoxide & 3.6 & 1578 \\
\hline Salvial-4(14)-en-1-one & 1.8 & 1585 \\
\hline Humuleneepoxide II & 3.5 & 1601 \\
\hline Aristoleneepoxide & 0.4 & 1604 \\
\hline Isopropyllaurate & 0.3 & 1614 \\
\hline 7-Hydroxyfarnesen & 0.8 & 1616 \\
\hline Widdrol & 0.7 & 1630 \\
\hline trans-Longipinocarveol & 0.5 & 1640 \\
\hline$\alpha$-Cadinol & 0.4 & 1643 \\
\hline Ledeneoxide II & 1.8 & 1659 \\
\hline Khusinol & 2.0 & 1673 \\
\hline 2-Ethylhexyl benzoate & 0.4 & 1768 \\
\hline Myristoleic acid & 0.2 & 1797 \\
\hline dilisobutylphtalate (artifact) & 0.1 & 1827 \\
\hline Heptadecan-2-one & 2.4 & 1832 \\
\hline Decan-2-yl benzoate & 0.2 & 1834 \\
\hline Methylpalmitate & 0.5 & 1908 \\
\hline di-Butyl phthalate (artifact) & 0.2 & 1918 \\
\hline Palmitic acid & 2.3 & 1960 \\
\hline Phytol & 1.1 & 2101 \\
\hline Tricosane & 0.2 & 2298 \\
\hline Pentacosane & 0.1 & 2499 \\
\hline
\end{tabular}

* RI exp-experimental retention index calculated on non-polar column; artifacts originate from plastic packaging

\subsection{Cell Culture Experiments}

\subsubsection{Cellular SOD and CAT Activity}

Based on the analysis of the composition and antioxidant potential of the extracts, two extracts with the highest potential were selected for cell culture. Catalase (CAT) activity ranged from 41.6 to $491.0 \mathrm{nmol} / \mathrm{min} / \mathrm{mg}$, and that of superoxide dismutase (SOD) ranged from 8.7 to $44.7 \mathrm{U} / \mathrm{mL}$. It was observed that the addition of a medium, i.e., DMSO, to cell culture increased enzyme activity, while the addition of fluoride caused its significant inhibition (FDR $\leq 0.05$ ). The addition of leaf extracts was associated with a significant increase in antioxidant enzyme activity compared to the negative control. When fluoride was added to the extracts, enzyme activity was reduced compared to the extracts alone, but it was still significantly higher than in the case of the culture subjected to the oxidative stress-inducing factor $(p \leq 0.05)$.

\subsubsection{Cellular Antioxidant Capacity}

A similar effect was observed with respect to antioxidant capacity measured by the ABTS (2,2'-azino-bis(3-ethylbenzothiazoline-6-sulfonic acid) assay. The lowest capacity was noted in the culture with sodium fluoride $(13.8 \mathrm{mM})$. The addition of plant extracts, even with the oxidative stress-inducing factor, significantly increased the antioxidant potential of the tested cells (Table 4). 
Table 4. Antioxidant potential in THP-1 cell cultures with Aegopodium podagraria leaf extracts (ABTS; enzyme activity: SOD—superoxide dismutase, CAT—catalase).

\begin{tabular}{|c|c|c|c|c|c|c|c|c|c|}
\hline \multirow{3}{*}{$\begin{array}{c}\text { Sample } \\
\text { Negative control }^{\mathrm{a}}\end{array}$} & \multicolumn{3}{|c|}{ ABTS } & \multicolumn{3}{|c|}{ SOD } & \multicolumn{3}{|c|}{ CAT } \\
\hline & \multicolumn{3}{|c|}{$[\mathrm{mM}]$} & \multicolumn{3}{|c|}{$[\mathrm{U} / \mathrm{mL}]$} & \multicolumn{3}{|c|}{ [nmol/min/mL/Protein] } \\
\hline & 14.7 & \pm & $0.2 * b, c, d, f, g, h, i$ & 31.4 & \pm & $6.4 * c, d, e, h, i$ & 51.3 & \pm & $8.1 * b, c, d$ \\
\hline Water (NaF solvent) ${ }^{b}$ & 36.7 & \pm & $7.8 * a, c, f, g, h, i$ & 30.1 & \pm & $3.1 * c, d, e, h, i$ & 138.7 & \pm & $5.0 * a, d, e, f$ \\
\hline DMSO (extract solvent) ${ }^{c}$ & 67.0 & \pm & $6.6 * a, b, d, e, f, g, h$ & 11.4 & \pm & $2.4 * a, b, f, g$ & 203.5 & \pm & $30.2 * a, e, f, g, h, i$ \\
\hline $\begin{array}{c}\text { DMSO + water (extract and } \\
\text { NaF solvent) } d\end{array}$ & 49.7 & \pm & $5.0 * a, c, e, f, g, h, i$ & 12.3 & \pm & $1.2 * a, b, f, g$ & 219.4 & \pm & $55.5 * a, b, e, f, g, h, i$ \\
\hline $\mathrm{NaF} 10 \mu \mathrm{M}^{\mathrm{e}}$ & 13.8 & \pm & $3.2 * b, c, d, f, g, h, i$ & 8.7 & \pm & $1.5 * a, b, f, g$ & 46.3 & \pm & $9.3 * b, c, d$ \\
\hline ethanol extract $25^{\circ} \mathrm{C} f$ & 113.0 & \pm & $8.2 * a, b, c, d, e, g, i$ & 44.7 & \pm & $12.4 * \mathrm{c}, \mathrm{d}, \mathrm{e}, \mathrm{h}, \mathrm{i}$ & 491.0 & \pm & $12.8 * a, b, c, d, e, g, h, i$ \\
\hline ethanol extract $25^{\circ} \mathrm{C}+\mathrm{NaF}$ g & 84.4 & \pm & $9.5 * a, b, c, d, e, f, h, i$ & 37.8 & \pm & $10.9 *$ d,e,h,i & 245.2 & \pm & $22.0 * a, b, e, f, h, i$ \\
\hline ethanol extract $80^{\circ} \mathrm{C}^{\mathrm{h}}$ & 99.3 & \pm & $3.1 * a, b, c, d, e, g, i$ & 10.0 & \pm & $2.6 * f, g$ & 272.1 & \pm & $9.6 * a, b, e, f, g, i$ \\
\hline ethanol extract $80^{\circ} \mathrm{C}+\mathrm{NaF}^{\mathrm{i}}$ & 69.4 & \pm & $5.1 * a, b, d, e, f, g, h$ & 12.0 & \pm & $2.8 * a, b, f, g$ & 140.1 & \pm & $31.9 * a, d, e, f$ \\
\hline
\end{tabular}

${ }^{*}$ FDR $p \leq 0.05$ between type of extract: $\mathrm{a}-$ Negative control, $\mathrm{b}$-Water (NaF solvent), $\mathrm{c}-$ Water (NaF solvent), $\mathrm{d}-\mathrm{DMSO}$ (extract solvent), $\mathrm{e}-\mathrm{DMSO}+$ water (extract and NaF solvent), $\mathrm{f}-\mathrm{NaF} 10 \mu \mathrm{M}, \mathrm{g}$ - ethanol extract $25^{\circ} \mathrm{C}, \mathrm{h}$ - ethanol extract $80^{\circ} \mathrm{C}, \mathrm{i}-\mathrm{ethanol}$ extract $80{ }^{\circ} \mathrm{C}+$ $\mathrm{NaF} ; n=5$.

\subsubsection{Anti-Apoptotic Activity of Leaf Extracts}

The effects of selected extracts on THP-1 cell survival were determined using the Annexin V-FITC Apoptosis Kit. Data analysis suggests that THP-1 cells grown in an environment containing fluoride at $10 \mu \mathrm{M}$ die mainly by late apoptosis and necrosis (A+/PI+). The majority of macrophages exposed to DMSO (extract medium) enter the pathway of late apoptosis and necrosis $(\mathrm{A}+/ \mathrm{PI}+)$. However, the observed fluorescence is more intense in cells incubated with sodium fluoride. Cells in the negative control and the control with water as fluoride medium were not observed to enter the apoptotic pathway. A small amount of cells in the early stages of apoptosis (A+/PI-) was noted in THP-1 cells with added extracts; hence, it may be concluded that they did not initiate apoptotic processes. The addition of sodium fluoride to the extracts promoted apoptosis (increased green fluorescence), and cells were shown to undergo late apoptosis and/or necrosis (red fluorescence). In this case, too, cell viability was greater than in the case of cultures with fluoride alone, demonstrating the protective effect of goutweed leaf extracts (Figure 2).

\subsubsection{Capacity of Intracellular ROS Decrease}

The addition of sodium fluoride at $10 \mu \mathrm{M}$ to the culture resulted in a marked increase in green fluorescence, indicating the enhanced production of free radicals. Increased ROS synthesis was also noted in the control with DMSO and in the control with DMSO and distilled water. A slight increase in the production of free radicals in the cytoplasm was observed after adding plant extracts to the cell culture. Compared to the culture with fluoride or DMSO, the increase in ROS generation was significantly smaller. Introduction into the cell culture of extracts with fluoride led to an increase in the production of free radicals, but it was significantly smaller compared to adding the factor inducing free radical reactions on its own; hence, the extracts were observed to produce an antioxidant effect (Figure 3).

Fluoride at $10 \mu \mathrm{M}$ was associated with a dramatic increase in the production of free radicals in the mitochondrion. Increased ROS synthesis was also noted in the control with DMSO and in the control with DMSO and distilled water. The addition of extracts to the cell culture led to a small increase in free radicals in the mitochondrion. Introduction into the cell culture of extracts with fluoride led to an increased production of free radicals, but again, it was lower than in the case of adding fluoride alone, pointing to the protective effect of plant extracts (Figure 4). 


\section{Control -}

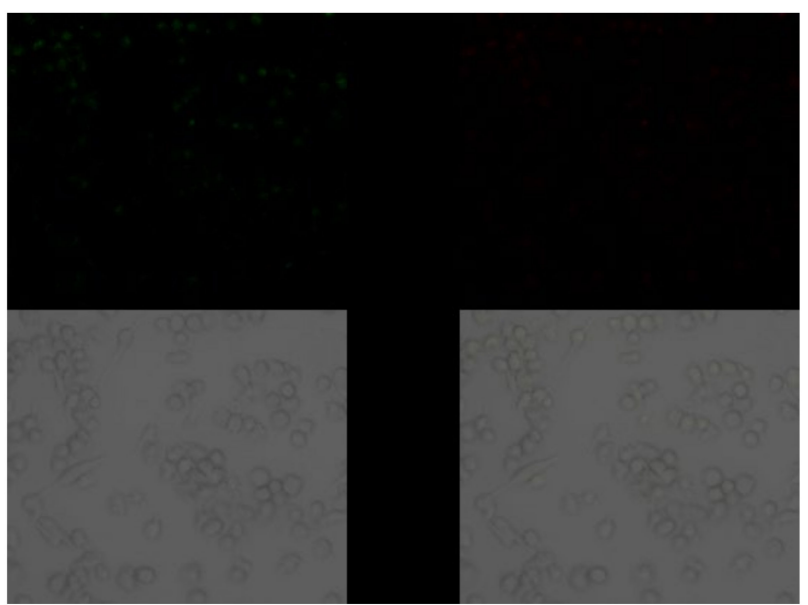

Control + (DMSO)

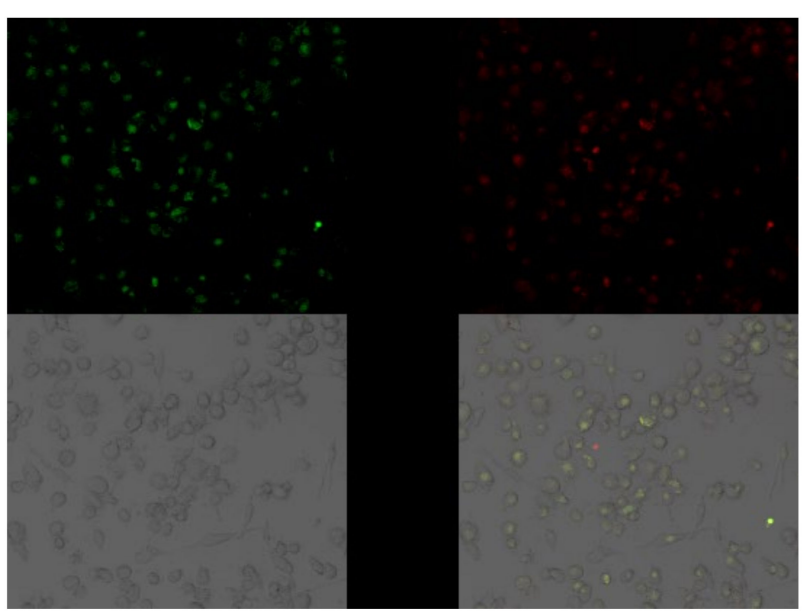

$\mathrm{NaF} 10 \mu \mathrm{M}$

\section{Control + (water)}

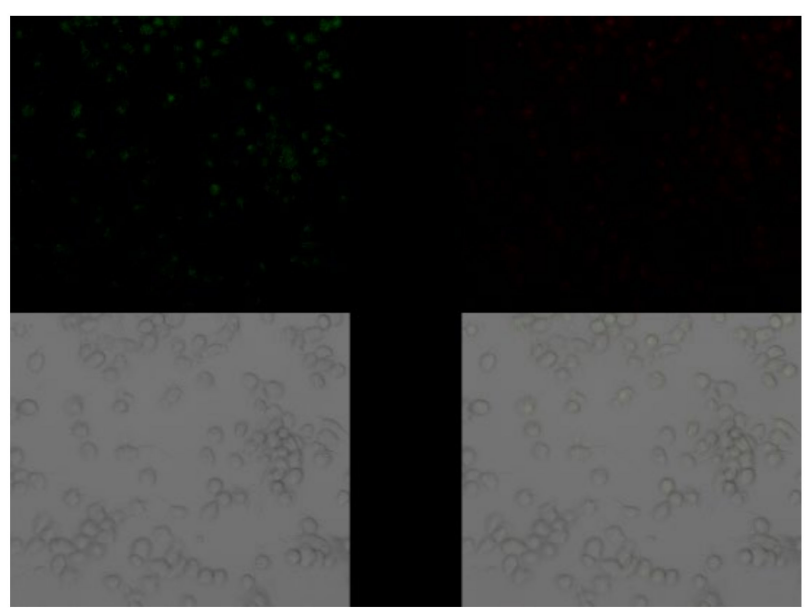

Control (DMSO + water)

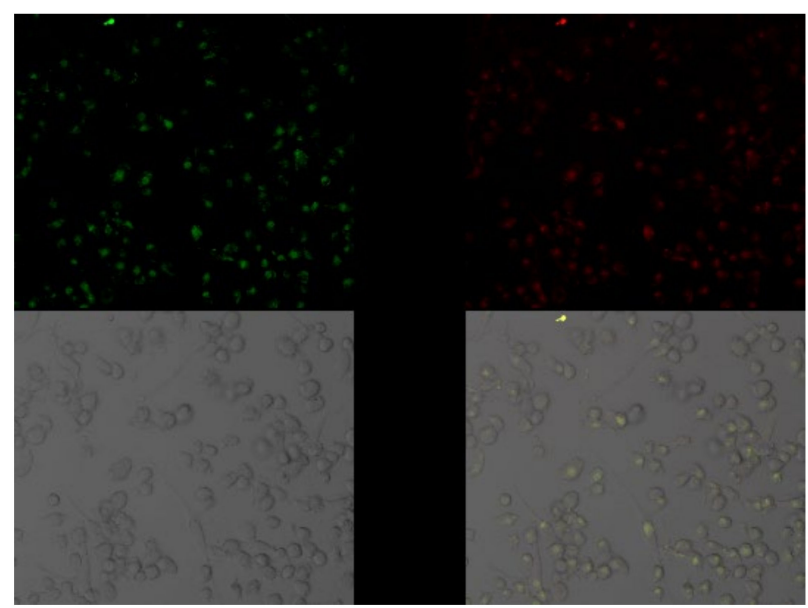

Figure 2. Cont. 


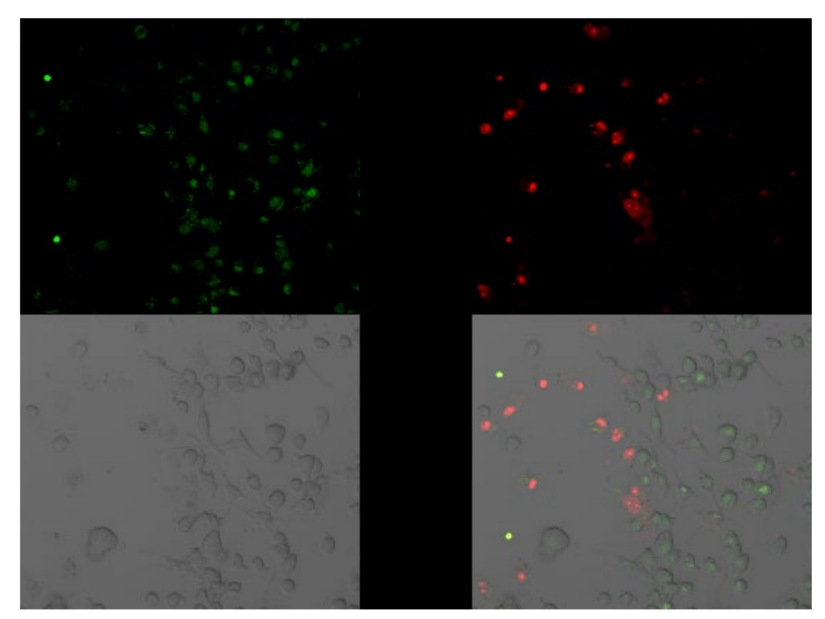

ethanol extract, $25^{\circ} \mathrm{C}+\mathrm{NaF}$

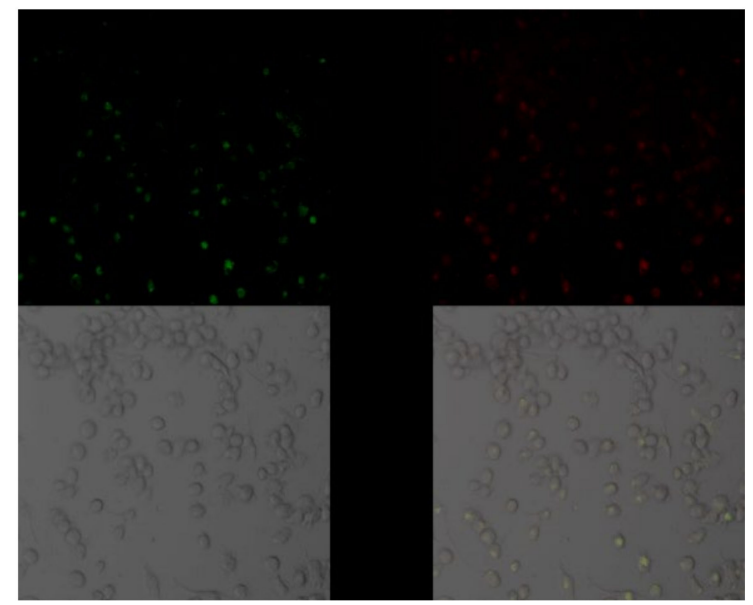

ethanol extract, $25^{\circ} \mathrm{C}$

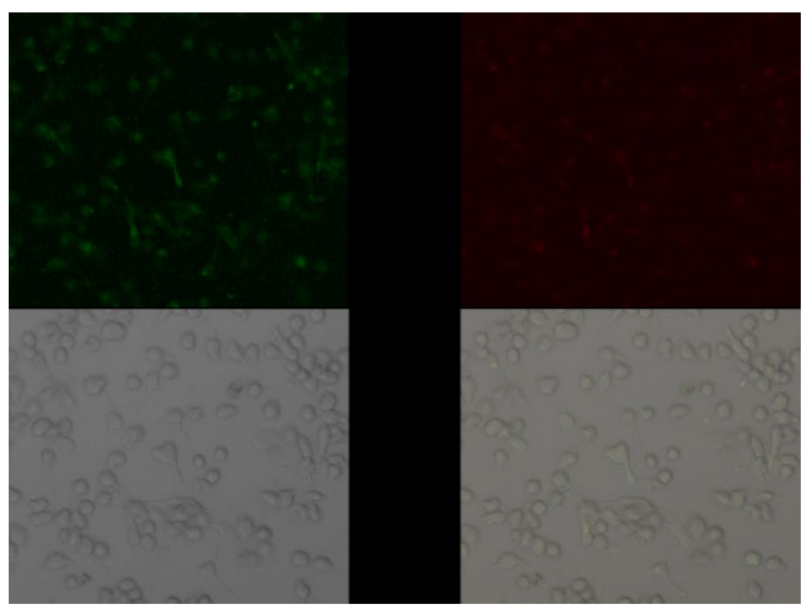

\section{ethanol extract, $80^{\circ} \mathrm{C}+\mathrm{NaF}$}

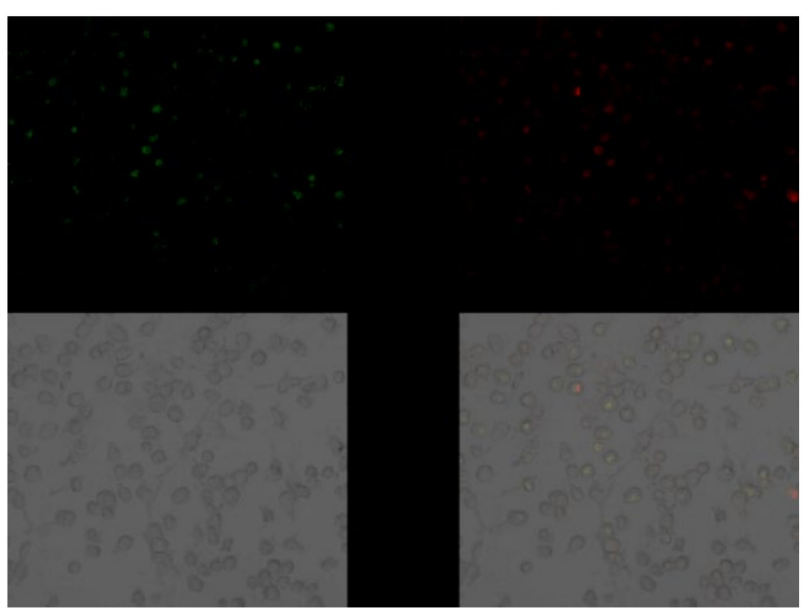

ethanol extract, $80^{\circ} \mathrm{C}$

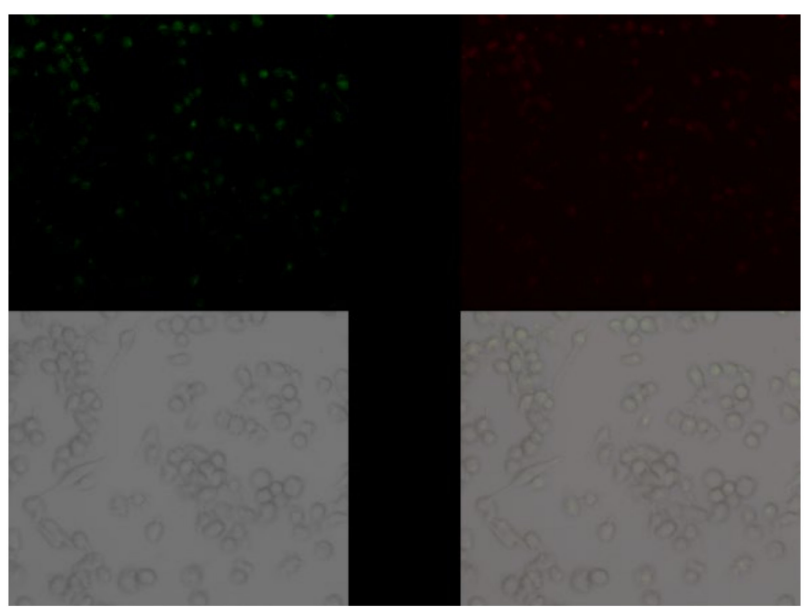

Figure 2. Imaging of apoptosis by confocal microscopy in macrophages cultured with NaF solutions alone or with ethanol extract. THP -1 were cultured with $\mathrm{NaF}$ and plant extract for $48 \mathrm{hr}$ as described in Materials and Methods. Cells that are viable are Annexin V-FITC and PI negative; cells that are in early apoptosis are Annexin V-FITC positive and PI negative (green fluorescence); and cells that are in late apoptosis or already dead (necrosis) are both Annexin V-FITC and PI positive (red fluorescence). A dual-pass FITC/rhodamine filter set was applied. 


\section{Control -}

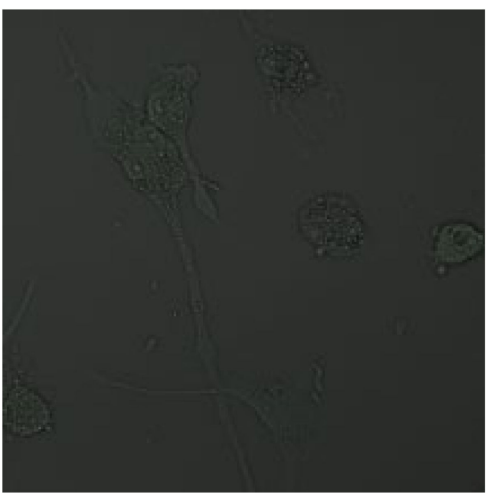

Control + (DMSO)

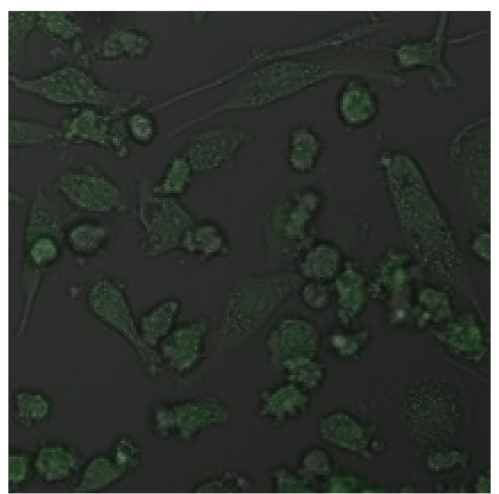

Control (DMSO + water)

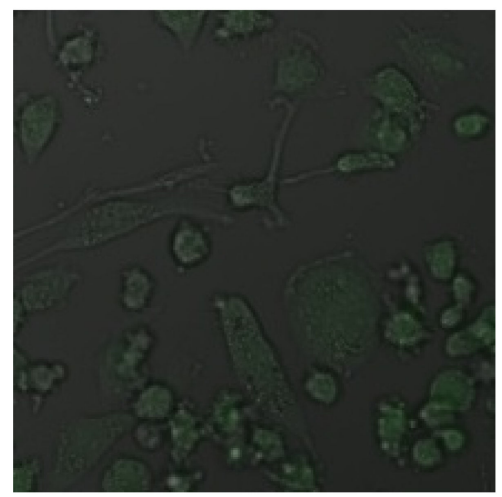

Ethanol extract, $25{ }^{\circ} \mathrm{C}+\mathrm{NaF}$

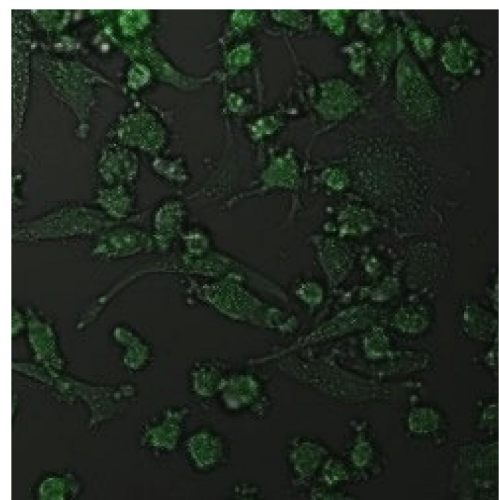

Ethanol extract, $25^{\circ} \mathrm{C}$

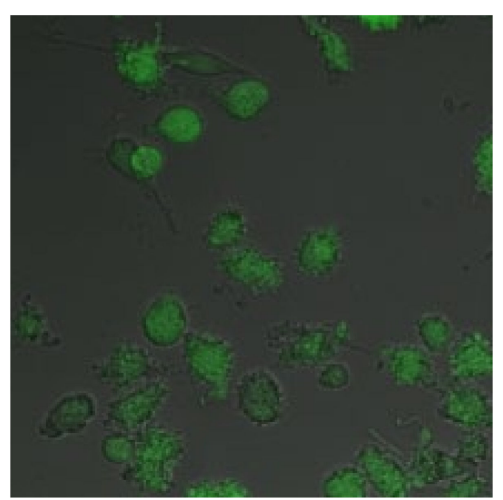

Ethanol extract, $80{ }^{\circ} \mathrm{C}+\mathrm{NaF}$

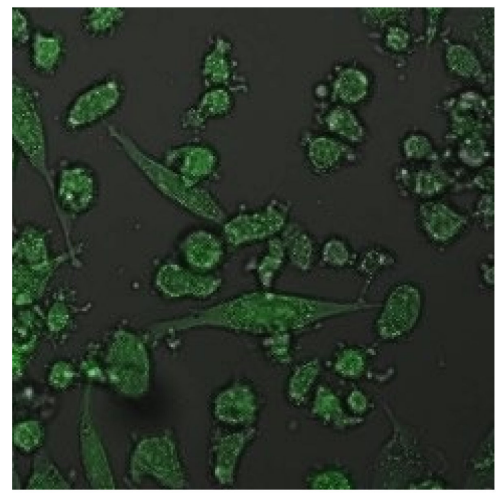

Ethanol extract, $80^{\circ} \mathrm{C}$

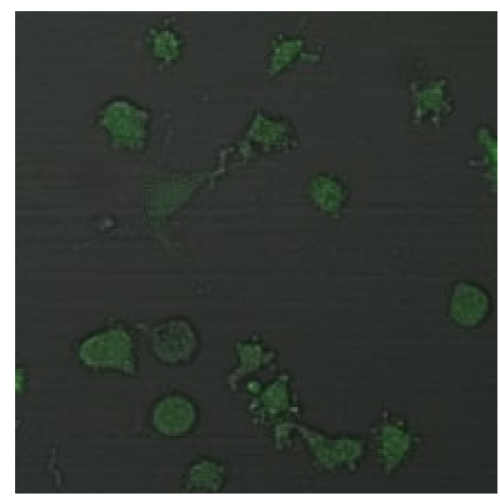

Control + (water)

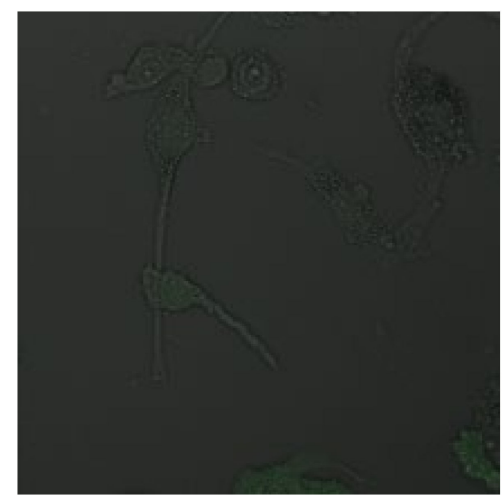

$\mathrm{NaF} 10 \mu \mathrm{M}$

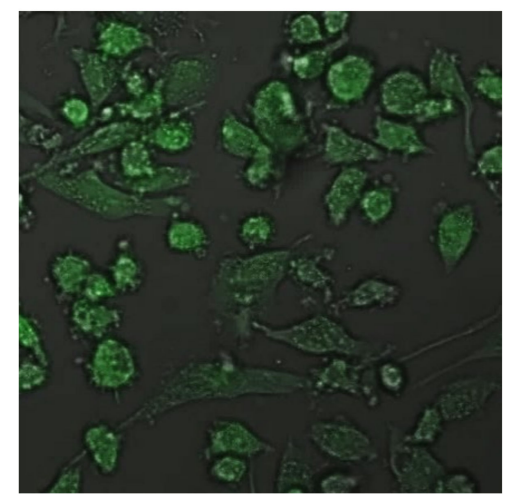

Figure 3. Imaging of cytoplasmatic superoxides detection by fluorescence microscopy in macrophages cultured with $\mathrm{NaF}$ solutions alone or with ethanol extract. 


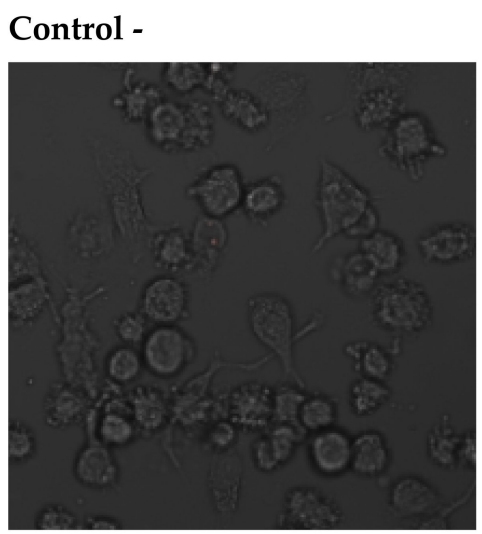

\section{Control + (DMSO)}

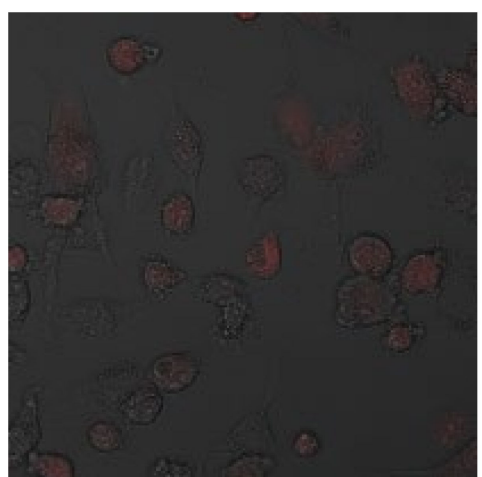

Ethanol extract, $25^{\circ} \mathrm{C}+\mathrm{NaF}$

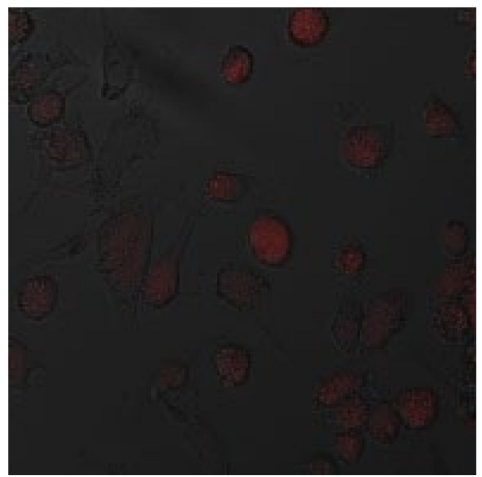

Ethanol extract, $25^{\circ} \mathrm{C}$

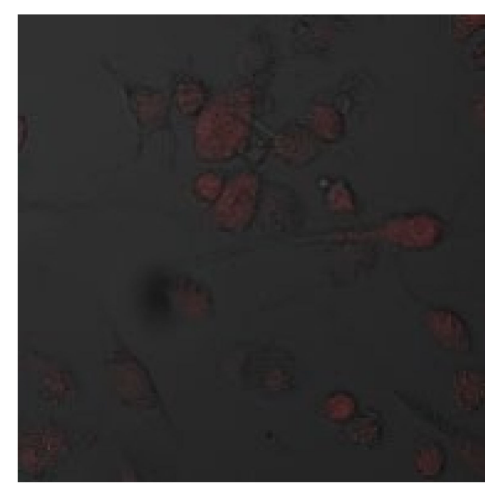

Control + (water)

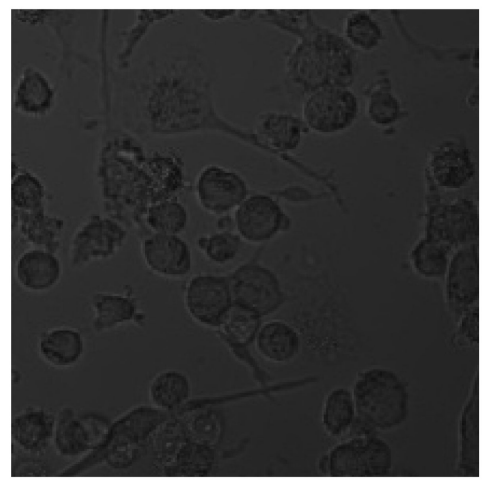

\section{Control (DMSO + water)}

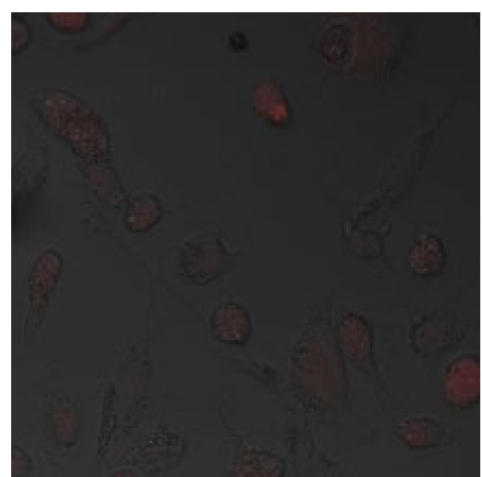

Ethanol extract, $80^{\circ} \mathrm{C}+\mathrm{NaF}$

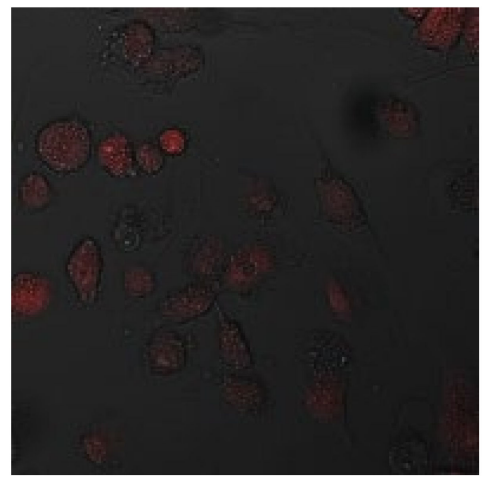

Ethanol extract, $80^{\circ} \mathrm{C}$

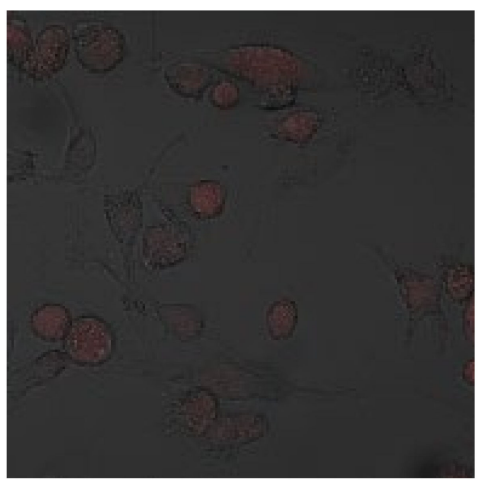

$\mathrm{NaF} 10 \mu \mathrm{M}$

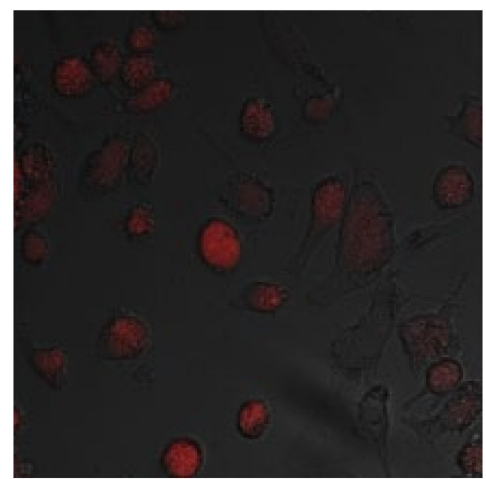

Figure 4. Imaging of mitochondrial superoxides detection by fluorescence microscopy in macrophages cultured with $\mathrm{NaF}$ solutions alone or with ethanol extract. $\mathrm{THP}^{-1}$ were cultured with $\mathrm{NaF}$ and extract for $48 \mathrm{~h}$ as described in the Materials and Methods. Detection of mitochondrial superoxide synthesis in macrophages was performed using MitoSOX Red indicator (incubation $10 \mathrm{~min} / 37^{\circ} \mathrm{C}$ ). The reagent is oxidised only by superoxide, and the oxidation product becomes highly fluorescent upon binding to nucleic acids (red fluorescence). 


\section{Discussion}

Plants are a valuable source of bioactive substances with antioxidant properties. Certain parameters, such as the degree of fragmentation, preservation method (e.g., lyophilisation), extraction conditions (e.g., duration, temperature, mixing) and choice of solvent have a significant impact on these properties [9-11]. It is important to learn how these factors affect the antioxidant potential of plant preparations in order to optimise extraction parameters and enhance the antioxidant activity of plant extracts.

3.1. Characteristics of the Source Material: Analysis of Essential Oils, Total Polyphenols and Polyacetylenes, and Antioxidant Capacity of Goutweed Extracts Obtained Using Different Solvents

Leaves are vegetative plant parts whose functions include transport, nutrition, as well as conditioning growth. The antioxidant properties of extracts may be attributed to the content of polyphenolic compounds, including flavonoids and phenolic acids, e.g., hydroxycinnamic and chlorogenic acid, essential oils, chiefly mono- and sesquiterpenes, carotenoids and antioxidant vitamins (vitamin E and C), as well as falcarinol and falcarindiol [2-12]. An increased intake of bioactive compounds, including polyphenols, has a positive effect on the body, notably by quenching oxidative stress [13,14]. Hydroxycinnamic acids, such as ferulic, caffeic, and p-coumaric acid, interrupt free radical chain reactions; they also donate electrons or hydrogen and stabilise the emerging phenoxyl radicals [9]. These compounds chelate transition metals, such as copper and iron, which play an essential role in the protection against oxidative stress, and they also inhibit the activity of enzymes producing reactive oxygen species. Chlorogenic acid, found in goutweed, has antioxidant properties, too [9-15]. Flavonoids, including quercetin and rutin, protect vitamin $\mathrm{C}$ against oxidation and take part in the chelation of metal ions, e.g., copper, acting as free radical scavengers as well (primary antioxidants). Individual polyphenolic compounds have different activities that may affect the antioxidant properties of plant extracts [2].

In this study, the extraction method was shown to impact on the overall content of polyphenols and polyacetylenes. TPC ranged from 4.98 to $13.96 \mathrm{mg} / \mathrm{L}$ of gallic acid. Higher concentrations were noted in extracts made with ethanol at $80{ }^{\circ} \mathrm{C}$. A similar relationship was observed for polyacetylenes, falcarinol and falcarindiol. Falcarinol content in extracts obtained with water at room temperature was below detection level, while at $80{ }^{\circ} \mathrm{C}$, it amounted to $46.91 \pm 3.47$. Falcarindiol content ranged from $185.81 \pm 19.21$ to $474.51 \pm 75.74 \mathrm{mg} / 100 \mathrm{~g}$ of the extract. Significantly higher levels $(p \leq 0.05)$ were observed in ethanol extracts made at higher temperatures, so it may be concluded that this extraction method improves the composition and properties of the product. Polyacetylenes found in goutweed have powerful anti-inflammatory effects, showing inhibitory activity against cyclooxygenases [5-7]. The falcarindiol content in essential oils isolated from leaves amounted to $0.6 \%$, and from stems, it amounted to $0.2 \%$ [5]. The effects of falcarinol and falcarindiol on the stress responses were studied in primary myotube cultures. Biphasic responses on cellular stress responses in myotube cultures were investigated by exposing them to various concentrations of falcarinol and falcarindiol for $24 \mathrm{~h}$. At low concentrations (1.6 to $25 \mu \mathrm{M}$ ), polyacetylenes caused a slightly accelerated intracellular ROS formation and increased cGPx transcription. The increased cGPx transcription may be interpreted as an adaptive response to the increased ROS formation. However, ROS formation, was substantially decreased after pre-incubation with both polyacetylenes at 50 and $100 \mu \mathrm{M}$, and cGPx transcription was reduced. In conclusion, pre-incubation with low concentrations of both polyacetylenes prior to $\mathrm{H}_{2} \mathrm{O}_{2}$ exposure induced a cytoprotective effect, whereas higher concentrations had adverse effects. Therefore, the effect is dose-dependent [6]. While falcarinol and falcarindiol are the main biologically active compounds in the Apiaceae family, research evidence in this scope is still insufficient.

Similar results were observed in clover extracts at $100 \mathrm{mg} / \mathrm{L}$. The TPC for white clover extracts amounted to $14.29 \mathrm{mg} / \mathrm{L}$, and for red clover extracts, it amounted to $19.20 \mathrm{mg} / \mathrm{L}$ of gallic acid [16]. In fresh and frozen goutweed leaves, TPC was determined

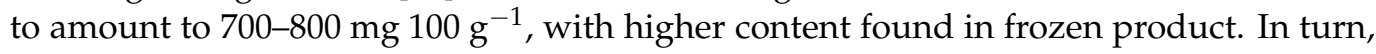


the main polyphenols were vanillic acid $3.56 \pm 0.15 \mathrm{mg} 100 \mathrm{~g}^{-1}$ and catechin hydrate

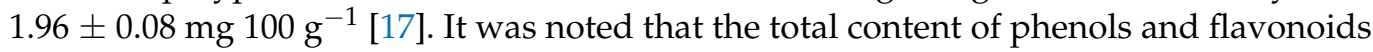
was directly proportional to extract concentration. In $10 \%$ extracts of goutweed, the total phenolic content was in the range $59.96-134.03 \mathrm{mg} / \mathrm{g}$ (of gallic acid equivalent), and it is these compounds that may be largely credited with the antioxidant activity of Apiaceae plant extracts. Extracts of Aegopodium podagraria L. were found to have the highest total phenolic content compared to other members of the Apiaceae family, that is Centella asiatica L. and Meum athamanticum [18].

Essential oils found in the plants from the Apiaceae family, especially monoterpenes, have high antioxidant capacity, which was confirmed in numerous studies [19-22]. Their properties are associated with reduced oxidative stress due to scavenging free radicals.

A total of 106 compounds, accounting for more than $87 \%$ of the whole oil, were identified in the essential oil of freeze-dried leaves of Aegopodium podagraria by GC-FID-MS. The dominant compound was spathulenol $(15.8 \%)$, an oxygenated derivative of sesquiterpene, followed by $n$-octanal (4.1\%), $\beta$-caryophylleneepoxide (3.6\%), humuleneepoxide II ( $3.5 \%)$, and $\beta$-pinene ( $3 \%$ ). Spathulenol is found, for example, in Origanum vulgare and Psidium guineense. It has been shown to possess antioxidant, anti-inflammatory, antiproliferative, and antimycobacterial activities [23]. The essential oil also contained many volatiles from different chemical groups. These results are partially consistent with those of other authors, leading to the conclusion that the country of origin and processing method significantly affect the chemical composition of the plant.

Goutweed from Russia collected during flowering contained a significant amount of sabinene (63\%) and other essential oil compounds i.e., $\alpha$-pinene (3.6\%), $\beta$-pinene (3.79\%), myrcene $(2.17 \%), \alpha$-thujone $(0.63 \%)$, dehydro-p-cymene $(3.39 \%)$, and $\beta$-phellandrene $(0.65 \%)$ [24]. Most of these compounds belonged to the monoterpene group. In a plant from Siberia (Russia), the essential oil contained $\alpha$-pinene (13.3\%), followed by limonene (9.4\%), p-cymene (8.8\%), (Z)- $\beta$-ocymene (5.2\%), $\beta$-pinene (5.0\%), germacrene D $(4.7 \%)$, spathulenol (4.4\%), $\alpha$-thujone (4.2\%), perillaldehyde (4.1\%), (E)- $\beta$-caryophyllene (3.9\%), (E)-caryophylleneoxide (3.4\%), and myrcene (3.4\%). The concentration of sabinene was only $1.8 \%$ [12]. Differences in the composition of essential oils between the leaves and stems of goutweed were observed in Estonia [3]. Higher levels of these bioactive compounds were present in stems $(3.8 \mathrm{mg} / \mathrm{g})$ than in leaves $(1.7 \mathrm{mg} / \mathrm{g})$. In leaves, the main compounds were monoterpenes, including $\beta$-pinene $(29.4 \%)$, limonene (18.4\%), $\alpha$-pinene $(15.7 \%)$, and $\gamma$-terpinene $(15.5 \%)$. Stems contained mainly monoterpenes $(44 \%)$, dominated by $\beta$-pinene $(11.1 \%)$, limonene (8.2\%), $\gamma$-terpinene $(8.2 \%)$, and $\alpha$-pinene $(6.6 \%)$, as well as sesquiterpenes $(29.8 \%)$, including germacrene D $(15.7 \%)$ and $(E)$ - $\alpha$-bergamotene $(4.8 \%)$ [5]. Our results show that the composition of essential oil from plants growing in Poland is dominated by oxygenated derivatives of sesquiterpenes, while the essential oils from goutweed collected in Russia and Estionia are mainly composed of monoterpenes such as $\alpha$-pinene, $\beta$-pinene, and sabinene.

The antioxidant potential of goutweed leaf extracts was determined using two spectrophotometric methods: DPPH and FRAP assays. By using four extraction techniques, we were able to identify the most effective extraction method and the best solvent. In this case, too, alcoholic extraction at a higher temperature was associated with higher antioxidant potential. With the DPPH assay, ethanol extraction at room temperature was found to be effective, too. Antioxidant activity, expressed as percentage inhibition of DPPH radical, ranged from 6.54 to $15.11 \%$, and in terms of reducing power, it ranged from 151.98 to $416.42 \mu \mathrm{M} \mathrm{Fe}(\mathrm{II}) / \mathrm{L}$. These results confirm that it is best to use several analytical methods for plant extracts. One method, often with limitations, will not fully reveal the potential of the plant. Most scientific studies support the use of higher temperatures to optimise the extraction of plant materials. In the case of our research, higher results for the temperature of $90 / 80^{\circ} \mathrm{C}$ were obtained in the FRAP method than in DPPH, but extracts prepared at a higher temperature had a higher concentration of TPC or polyacetylenes, which may also affect the obtained results. These findings are consistent with those made by Valyova et al., 
who observed the highest antioxidant capacity (DPPH and ABTS) in ethanol extracts, and high antioxidant potential in the plant itself (respectively, $\mathrm{EC}_{50} 66 \mu \mathrm{g} \mathrm{mL} \mathrm{L}^{-1}$ for DPPH and $\mathrm{IC}_{50} 25 \mu \mathrm{g} \mathrm{mL} \mathrm{m}^{-1}$ for ABTS assay) [25]. However, the authors did not provide information on the part of the plant the extracts were made from, and the concentration used was ten times higher than that used in this study. Similar findings were obtained in a study of extracts $(100 \mu \mathrm{L} / \mathrm{mL})$ made from dry plants by ultrasonic bath extraction method, where $\mathrm{IC}_{50}$ amounted to $64.740 .22 \mathrm{~L} / \mathrm{mL}$ [26]. The $10 \%$ extract of the common goutweed showed very high antioxidant potential at $80 \%$ inhibition of DPPH radical, while the $1 \%$ extract showed antioxidant potential at $\approx 15 \%$ inhibition of DPPH radical, with $\mathrm{EC}_{50}$ amounting to $3.8 \%$ [18]. These results are consistent with the present findings. The high antioxidant potential (>90\% inhibition of DPPH) of various parts of the common goutweed was also demonstrated by Wróblewska et al., who investigated a range of different extraction parameters. The authors found ultrasonic-assisted extraction with the use of ethanol to be the most advantageous [10]. Additionally, it was confirmed that spathulenol, the main essential oil compound isolated in our study, exhibited the highest antioxidant activities in the DPPH and MDA system compared with the reference standard $\left(\mathrm{IC}_{50}\right.$ values ranging from 26.13 to $85.60 \mu \mathrm{g} / \mathrm{mL}$ ) [23].

The duration and temperature of extraction are important parameters for process optimisation, even in order to minimise the cost of energy used in the process. Lyophilisation (freeze drying) was shown not to alter the composition and antioxidant properties of extracts, making it a good method for preserving plant products [27,28]. Moreover, fragmentation of plant material may help shorten extraction time and increase the amount of bioactive compounds released into the extract [28]. Additionally, fragmentation increases the specific surface area, allowing for more effective mixing of the product with the solvent. With regard to the above, the harvested leaves were frozen, freeze-dried, and homogenised.

In the majority of cases, a higher extraction temperature was associated with greater antioxidant activity. The higher antioxidant potential noted in extracts made at $80 / 90{ }^{\circ} \mathrm{C}$ may be related to the increased substance solubility and diffusion coefficient at higher temperatures [28]. The medicinal properties of plant preparations are significantly dependent on the choice of solvent at every stage of research, whether it is used in the extraction process or to dissolve the solution for the purposes of analysis or to obtain the final concentration. What is more, antioxidants may be isolated from plant material using a range of different techniques and solvents because of the chemical diversity of those compounds [29]. In folk medicine as well as in modern phytotherapy, the most common solvents are water and alcohol. They are used to obtain infusions and macerates (aqueous or alcoholic). In cell line studies, DMSO is used among others as a medium introducing the extract into the cells; hence, in our spectrophotometric analyses, different solvents were used (DMSO, water, ethanol) in order to observe the differences arising from the use of different solvents commonly used in phytotherapy and cell models. It was determined that the best extraction method involved the use of ethanol at $80^{\circ} \mathrm{C}$. Extraction with ethanol at room temperature was found to be effective, too. Therefore, it can be concluded that ethanol as an extracting agent increased the antioxidant capacity of extracts to a greater extent than water. Other authors also reported that ethanol, because of its properties, was a better solvent in the case of plant products than water [27]. The observed results may be related to the hydrophilic properties and polarity of bioactive compounds isolated from plants [30]. The varied polarity of extracted components and solvents used may determine the properties of the extract [31]. Ethanol is a moderately polar organic solvent, whereas water is highly polar. In turn, DMSO is a highly polar aprotic solvent. Water is good at dissolving ions and polar molecules but poor at dissolving nonpolar molecules, e.g., organic compounds such as hydrocarbons and their derivatives. Therefore, the chemical composition of extracts determines their properties. The present findings are consistent with those made by Valyova, who studied goutweed extracts made with the use of different solvents, observing the highest antioxidant capacity in ethanol extracts [25]. With respect to FRAP and Folin-Ciocalteau assays, the differences between solvents (DMSO, 
water/ethanol) were minor and for the most part did not have a significant effect on the antioxidant potential of extracts. In the above analyses, extracts dissolved in water/ethanol had more powerful antioxidant properties than those dissolved in DMSO. The opposite was observed for the DPPH method. DMSO increased the potential in extracts, and the differences between solvents were considerable and statistically significant $(p \leq 0.05)$.

The presented data confirm that goutweed extracts may provide a valuable source of natural antioxidants, including but not limited to polyphenols, essential oils, and polyacetylenes. In addition, determining the effects of various parameters on the healthpromoting properties of extracts made it possible to choose the extraction method and temperature maximising their antioxidant potential.

\subsection{Study of the Antioxidant Response of Macrophages Exposed to Goutweed Extracts}

Our study is the first to report on the antioxidant effects of Aegopodium podagraria extracts on cell lines. In order to study the cellular antioxidant response of macrophages exposed to goutweed leaf extracts, we determined the total antioxidant capacity by ABTS method, activity of antioxidant enzymes (CAT, SOD), as well as mitochondrial and cytoplasmic generation of free radicals.

Sodium fluoride was used in this study to induce oxidative stress in macrophages. Fluoride toxicity has been well documented, and its mechanism is related, among others, to the disturbance of redox balance. Our study demonstrated that fluoride significantly reduced the total antioxidant capacity measured by ABTS and the activity of antioxidant enzymes: catalase and superoxide dismutase. Additionally, it enhanced oxidative stress by upregulating the production of oxygen free radicals, especially superoxide anion radical in the mitochondrion and cytosol, which has also been observed in other studies [16-32]. It may be concluded that high concentrations of fluoride $(10 \mu \mathrm{M})$ inhibit antioxidant enzymes and undermine the functionality of the "antioxidant apparatus". These results are consistent with the reports of other authors, who likewise demonstrated the inhibition of the above enzymes by fluoride [33,34].

Extracts added to cell cultures were shown to effectively quench oxidative stress by boosting the antioxidant capacity of cells (ABTS) as well as the activity of antioxidant enzymes. The addition of extracts into the cell culture unblocked enzymes, which were previously inhibited by fluoride. The elements found in extracts supplied the necessary cofactors for antioxidant enzymes, which were previously blocked by the highly reactive sodium fluoride, facilitating the cell defence system. Polyphenols, polyacetylenes, and essential oils found in extracts may enhance the activity of antioxidant enzymes, including superoxide dismutase, catalase, and glutathione peroxidase, as well as contribute to increasing the concentrations of small-molecule antioxidants, improving the total antioxidant capacity of cells [16]. Similar findings were made in a macrophage study, where sodium fluoride also suppressed antioxidant capacity and inhibited enzyme activity, while extracts of red and white clover effectively unblocked the activity of those enzymes and produced antioxidant effects [16].

In this study, we also determined the mitochondrial and cytoplasmic generation of oxygen free radicals. The increased generation of free radicals, both in the mitochondrion and cytoplasm, was observed in the presence of DMSO and sodium fluoride; however, extracts were shown to exert a protective effect against the free radical activity of sodium fluoride. Research findings are conclusive that sodium fluoride at $10 \mu \mathrm{M}$ initiates cell death. The proapoptotic and necrotic effects of fluoride are related to initiating oxidative stress and boosting the production of superoxide anion radicals. Fluoride also alters the activity of antioxidant enzymes and initiates inflammation, interfering with the defensive mechanisms in cells [33-35]. Apoptosis and necrosis initiation was also observed in THP-1 macrophages with DMSO (1\%) added to cell culture as a goutweed extract medium. Our study is consistent with the literature, confirming the negative effect of this solvent even in small concentrations [36-39]. Therefore, DMSO is not a neutral solvent for cells, and its use-even in small concentrations $(>0.5 \%)$ - as a medium for plant extracts interferes 
with their action. The effects of low concentrations of DMSO (0.1-2\%) on the antioxidant status in plant cells were investigated in an in vitro study. Elevated stress levels were observed in direct proportion to the concentration of DMSO added to the cell culture [40]. In this study, the addition of DMSO as a control for extracts in macrophages enhanced the antioxidant capacity of cells, as well as catalase activity, while at the same reducing the activity of superoxide dismutase compared to the negative control. This solvent initiated the generation of reactive oxygen species, at the same inducing oxidative stress, which increases the activity of catalase- a free radical scavenging enzyme. Therefore, it may be concluded that DMSO, even in a low concentration $(1 \%)$, has an adverse effect on the redox balance and enzyme activity.

\section{Materials and Methods}

\subsection{Plant Material}

Leaves of goutweed (Aegopodium podagraria L.) gathered before flowering in June from green areas $\left(53^{\circ} 28^{\prime} 11.002^{\prime \prime} \mathrm{N}, 14^{\circ} 29^{\prime} 46.7982^{\prime \prime} \mathrm{E}\right)$ served as the study material for this research. The harvested plant $(2 \mathrm{~kg})$ was assessed by a botanist. The collected leaves underwent lyophilisation in a lyophilisator $\left(0.735 \mathrm{mmHg} /-20^{\circ} \mathrm{C}\right.$; Alpha 1-2 LD plus) and were then subjected to homogenisation by grinding to a powder in a food homogeniser (FOSS 2094). The steps of the study are presented in Figure 5.

1)

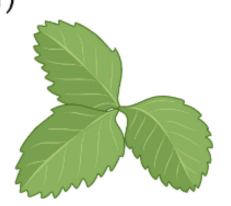

Aegopodium podagraria $\mathrm{L}$.

3)
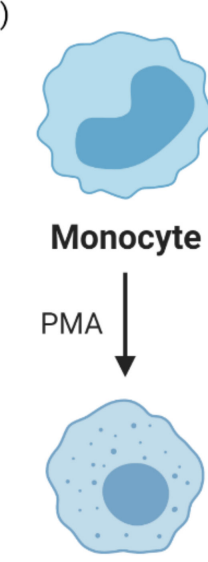

Macrophage

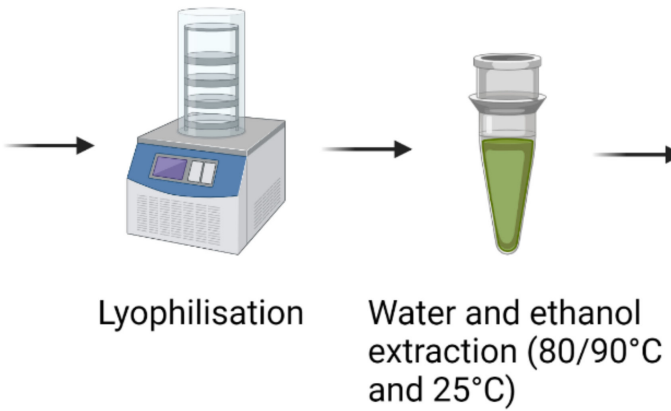

4)

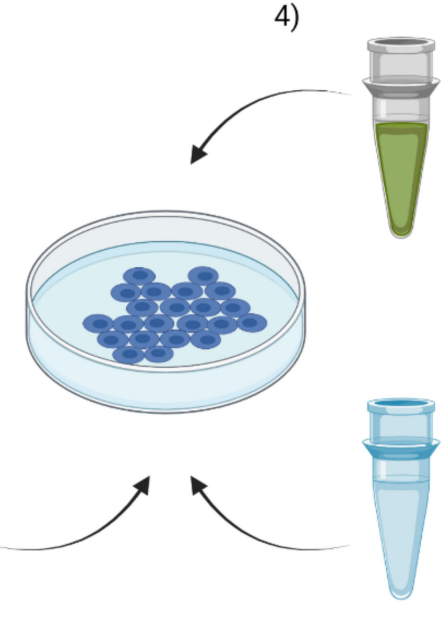

Aegopodium podagraria L. extract

$10 \mu \mathrm{M}$ of $\mathrm{NaF}$
2) Polyacetylenes (Falcarinol and falcarindiol)

Essential Oil (106 compounds) Antioxidant potential
(DPPH, FRAP)

Total polyphenols content
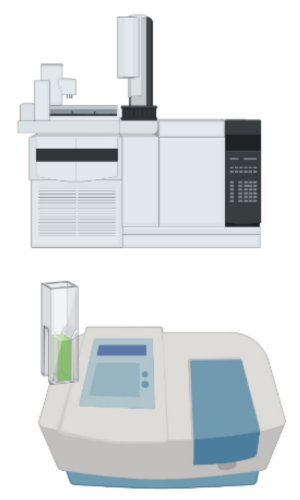
factor initiating oxidative stress
5) Activity of antioxidant enzymes (SOD, CAT)

Total antioxidant potential (ABTS)

ROS generation

Apoptosis process
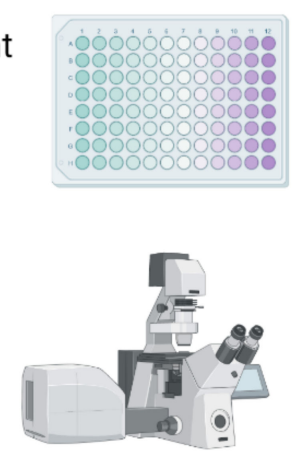

Figure 5. Methodology used to study Aegopodium podagraria L. extracts. Created with BioRender.com.

\subsection{Preparation of an Aqueous Extract}

Distilled water $(150 \mathrm{~mL})$ at $90{ }^{\circ} \mathrm{C}$ or $25^{\circ} \mathrm{C}$ was poured over approximately $1.5 \mathrm{~g}$ of dried goutweed powder. A closed conical flask with the mixture was placed on a vortex mixer and gently shaken (180 RPM) for $10 \mathrm{~min}$. The mixture was cooled down to room 
temperature and filtered. From the obtained filtrate, water was evaporated under reduced pressure. The obtained aqueous extract was placed in a plastic vial and then stored at $-20{ }^{\circ} \mathrm{C}$ until used [16].

\subsection{Preparation of Ethanol Extract}

Approximately $1.5 \mathrm{~g}$ of dried goutweed powder was transferred into $150 \mathrm{~mL}$ of $96 \%$ ethanol (Chempur, Poland). The mixture was kept for $30 \mathrm{~min}$ at boiling point $\left(80^{\circ} \mathrm{C}\right)$ or at $25{ }^{\circ} \mathrm{C}$ in a water bath under a condenser. In order to maintain a uniform boiling process, a few boiling stones were added to the flask. Then, the mixture was cooled down to room temperature and filtered. Alcohol was subsequently evaporated under reduced pressure. The obtained alcohol extract was placed in a plastic vial and then stored at $-20{ }^{\circ} \mathrm{C}$ until use [16].

\subsection{Preparation of Extracts for Analysis}

Extracts were dissolved in 96\% ethanol (Chempur, Poland) (for ethanol extracts), in distilled water (for aqueous extracts) and in DMSO (Sigma-Aldrich, Poland) to compare solvents used in phytotherapy with a cellular carrier (DMSO) at the $100 \mathrm{mg} / 1$ concentration [16-32].

\subsection{Antioxidant Activity of Extracts by the DPPH Method}

The antioxidant activity of samples was measured spectrophotometrically using synthetic radical DPPH (2,2-diphenyl-1-picrylhydrazyl) (Sigma-Aldrich, Poznan, Poland) and an Agilent 8453UV spectrophotometer. First, 96\% ethanol, $1 \mathrm{~mL}$ of $0.3 \mathrm{mM}$ solution of $\mathrm{DPPH}$ in $96 \%$ ethanol, and $0.1 \mathrm{~mL}$ of the test sample were introduced into the vial with a v/v ratio of 29:10:1. After mixing, the solution was placed for $30 \mathrm{~min}$ in a dark place. During this time, the so-called A0 solution was prepared by mixing $96 \%$ ethanol and $0.3 \mathrm{mM}$ solution of DPPH in a $\mathrm{v} / \mathrm{v}$ ratio of 3:1. As a reference solution, $96 \%$ ethanol was used. Before measurement, the contents of the vial were thoroughly mixed, poured into quartz cuvettes, and spectral absorbance was immediately measured at $518 \mathrm{~nm}$ [41]. All assays were performed in triplicate.

\subsection{Determination of the Reduction Potential of Extracts by the FRAP Method}

The FRAP method, used to determine the total reduction potential, tests the capability of the test sample to reduce $\mathrm{Fe}^{3+}$ ions to $\mathrm{Fe}^{2+}$ ions. These ions are complexed by TPTZ (2,4,6-tris(2-pyridyl)-1,3,5-triazine) (Sigma-Aldrich, Poznań, Poland), creating an intense blue colour with the maximum absorbance at $593 \mathrm{~nm}$. The antioxidant capacity of the sample is determined by comparing changes in absorbance $\Delta \mathrm{A}$ with the value $\Delta \mathrm{A}$ of the standard solution $\mathrm{Fe}^{2+}$ (calibration curve). The FRAP unit represents the ability to reduce 1 mole $\mathrm{Fe}^{3+}$ to $\mathrm{Fe}^{2+}$ [42-44]. The solution was mixed and incubated for 4-5 min in a laboratory drier at $37^{\circ} \mathrm{C}$. Then, the solution was mixed thoroughly and transferred to a cuvette for absorbance at $593 \mathrm{~nm}$. All assays were performed in triplicate.

\subsection{Determination of Polyacetylenes}

Falcarinol and falcarindiol were determined by gas chromatography coupled with mass spectrometry (GC-MS QP2010 PLUS, Shimadzu, Kyoto, Japan). Ethanol extracted samples were dried and amounts of ca. $50 \mathrm{mg}$ were dissolved in ethanol. Solutions were centrifuged and analysed chromatographically. Compounds were separated using a ZB5MSi $(30 \mathrm{~m} \times 0.25 \mathrm{~mm} \times 0.25 \mu \mathrm{m})$ capillary column (Phenomenex Inc., Torrance, CA, USA) with helium as a carrier gas $(0.9 \mathrm{~mL} / \mathrm{min})$. The injector temperature was set at $230{ }^{\circ} \mathrm{C}$, and the column temperature was programmed as follows: $70^{\circ} \mathrm{C}$, a subsequent increase to $230{ }^{\circ} \mathrm{C}$ at the rate of $15^{\circ} \mathrm{C} / \mathrm{min}$., to $310^{\circ} \mathrm{C}$ at the rate of $3{ }^{\circ} \mathrm{C} / \mathrm{min}$., and then held for $10 \mathrm{~min}$. The GC-MS interface and ion source temperatures were set at $240{ }^{\circ} \mathrm{C}$, ionisation energy was set at $70 \mathrm{eV}$. The total ion current (TIC) mode (40-200 m/z range) was used. Compounds were identified on the basis of their mass spectra compared with mass spectral 
libraries (NIST08 library, Shimadzu, Kyoto, Japan). A quantitative analysis was carried out in SIM mode (129 m/z) with a calibration curve using falcarinol (Sigma-Aldrich, Poland) as an external standard.

\subsection{Determination of the Total Phenolic Content (TPC) in Extracts}

Polyphenol content was determined using the Folin-Ciocalteu reagent. First, $5.0 \mathrm{~mL}$ of a 10\% Folin-Ciocalteu (Chempur, Poland) solution and $1.0 \mathrm{~mL}$ of the test sample were successively introduced into a vial. The sample was shaken vigorously, and after $5 \mathrm{~min}$, $4.0 \mathrm{~mL}$ of $7.5 \% \mathrm{Na} 2 \mathrm{CO} 3$ (Chempur, Poland) solution was added. The prepared solution was incubated for $60 \mathrm{~min}$ at room temperature. Absorbance at $765 \mathrm{~nm}$ was measured. The polyphenol content was determined from the calibration curve using gallic acid (SigmaAldrich, Poznań, Poland) as a reference standard. All tests were performed in triplicate. The results are shown in $\mathrm{mg} / \mathrm{L}$ gallic acid (GAE) [11].

\subsection{Isolation of Essential Oil}

Essential oil from the aerial parts (freeze-dried leaf) of Aegopodium podagraria L. was obtained by hydrodistillation using a Clevenger-type apparatus. Hydrodistillation was conducted for $4 \mathrm{~h}$ using $150 \mathrm{~g}$ of dried plant material. The yellowish essential oil was dried over anhydrous magnesium sulphate and stored at $4{ }^{\circ} \mathrm{C}$ in the dark until tested and analysed.

\subsection{Identification of Essential Oil Constituents}

Constituents of the essential oil were identified based on their mass spectra compared with those from mass spectra libraries: NIST 2012, Wiley Registry of Mass Spectral Data 8th edition, and MassFinder 4.1, along with the relative retention indices (RI) on DB-1 column (available from MassFinder 4.1).

\subsection{Analysis of Essential Oil}

GC-MS-FID analysis of the essential oil was performed on a Trace GC Ultra Gas Chromatograph coupled with a DSQII mass spectrometer (Thermo Electron, Waltham, MA, USA). Simultaneous GC-FID and GC-MS analyses were performed using a MS-FID splitter (SGE Analytical Science, Ringwood, VIC, Australia). The mass range was 33-550 amu, ion source-heating: $200{ }^{\circ} \mathrm{C}$; ionisation energy: $70 \mathrm{eV}$. One microlitre of essential oil solution $(80 \% \mathrm{v} / \mathrm{v})$ diluted in pentane/diethyl ether was injected in split mode at a split ratios (50:1). Operating conditions: capillary column Rtx-1 MS (60 $\mathrm{m} \times 0.25 \mathrm{~mm}$ i.d., film thickness $0.25 \mu \mathrm{m})$, and temperature program: $50{ }^{\circ} \mathrm{C}(3 \mathrm{~min})-300^{\circ} \mathrm{C}(30 \mathrm{~min})$ at $4 \circ \mathrm{C} / \mathrm{min}$. Injector and detector temperatures were $280^{\circ} \mathrm{C}$ and $300^{\circ} \mathrm{C}$, respectively. The carrier gas was helium (constant pressure: $300 \mathrm{kPa}$ ). The relative composition of each essential oil sample was calculated from GC peak areas according to total peak normalisation, which is the most popular method used in essential oil analysis.

\subsection{Cell Cultures}

The monocytic cells, THP-1 line of the American Type Collection (ATCC, Rockville, MD, USA), cultivated on 6-well plates $\left(2 \times 10^{6}\right.$ cells), were differentiated into macrophages by adding $10 \mu \mathrm{L}$ of phorbol ester (PMA, $100 \mathrm{nM}$ ) to the culture medium RPMI (Wytwórnia Szczepionek i Surowic, Lublin, Poland) that included $10 \%$ of the foetal bovine serum (FBS) (Gibco, Paisley, UK), penicillin (100 U/mL), and streptomycin $(100 \mathrm{mg} / \mathrm{mL})($ SigmaAldrich, Poznań, Poland). The cells were incubated in standard conditions $\left(37^{\circ} \mathrm{C}\right.$ and $5 \%$ $\mathrm{CO}_{2}$ ) for $24 \mathrm{~h}$. Next, the adherent macrophages were washed three times with PBS. The cells were incubated for $48 \mathrm{~h}$ with the factors: $\mathrm{NaF}$ at a concentration of $10 \mu \mathrm{M}$, causing oxidative stress [16] and/or extracts of goutweed with a final concentration of $100 \mathrm{mg} / \mathrm{mL}$ [16-32]. Plant extracts were dissolved in DMSO at a concentration not exceeding 1\%. Two extracts with the highest antioxidant potential obtained in spectrophotometric studies were selected for in vitro tests. The positive control for fluorine was distilled water, for the extracts 
from the plant, it was DMSO, while for both variants introduced to the culture, it was simultaneously water and DMSO. The concentrations of the added fluorides were chosen based on the results of human serum studies carried out by other authors. After $48 \mathrm{~h}$ of incubation, the cells were scrapped and centrifuged, and the resulting cell pellets were used in spectrophotometric measurements. The experiment was repeated 5 times. Protein concentration was measured using the Micro BCA Protein Kit (Thermo Fisher Scientific, Waltham, MA, USA).

\subsection{Measurement of the Total Antioxidant Potential (ABTS) and the Activity of Antioxidant Enzymes}

Antioxidant potential was measured using the Antioxidant Assay Kit (Cayman Chemical Company). The kit measures the total antioxidant capacity of cell lysates. The activity of antioxidant enzymes was measured using the Superoxide Dismutase Assay Kit, Catalase Assay Kit (Cayman Chemical Company). The antioxidant potential was measured spectrophotometrically at $405 \mathrm{~nm}$ and presented in the form of $\mathrm{mM}$. Catalase activity was measured spectrophotometrically at $540 \mathrm{~nm}$ and presented in $\mathrm{nmol} / \mathrm{min} / \mathrm{mL} /$ protein. The activity of superoxide dismutase was measured spectrophotometrically by estimating the amount of the superoxide anion in room temperature at $440 \mathrm{~nm}$ and presented in [U/mL]. The intensity of the reaction produced in the reaction was measured in a microplate reader (Biogent).

\subsection{Imaging of Intracellular ROS Generation}

The intracellular generation of reactive oxygen species (ROS) was visualized by MitoSOX ${ }^{\mathrm{TM}}$ Red reagent (Thermo Fisher Scientific, Waltham, MA, USA), which is a novel fluorogenic dye for highly selective superoxide detection in the mitochondria of live cells. Cells were loaded with $5 \mu \mathrm{M}$ MitoSOX ${ }^{\mathrm{TM}}$ reagent working solution and incubated for 10 min at $37{ }^{\circ} \mathrm{C}$ (humidified $95 \%$ air $/ \mathrm{CO}_{2}$ atmosphere at $37^{\circ} \mathrm{C}$ ), protected from light. The concentration of the MitoSOX ${ }^{\mathrm{TM}}$ reagent working solution should not exceed $5 \mu \mathrm{M}$. After incubation, the cells were washed gently three times with a warm buffer at room temperature, and the preparations were examined under a confocal microscope (Olympus, $\mathrm{SV}$ 1000). Once in the mitochondria, MitoSOX ${ }^{\mathrm{TM}}$ Red reagent is oxidised by superoxide but not by other reactive oxygen (ROS) or nitrogen (RNS) species, showing red fluorescence. The oxidation product becomes highly fluorescent upon binding to nucleic acids (excitation at $510 \mathrm{~nm}$, emission at $580 \mathrm{~nm}$ ) (Figure 6).

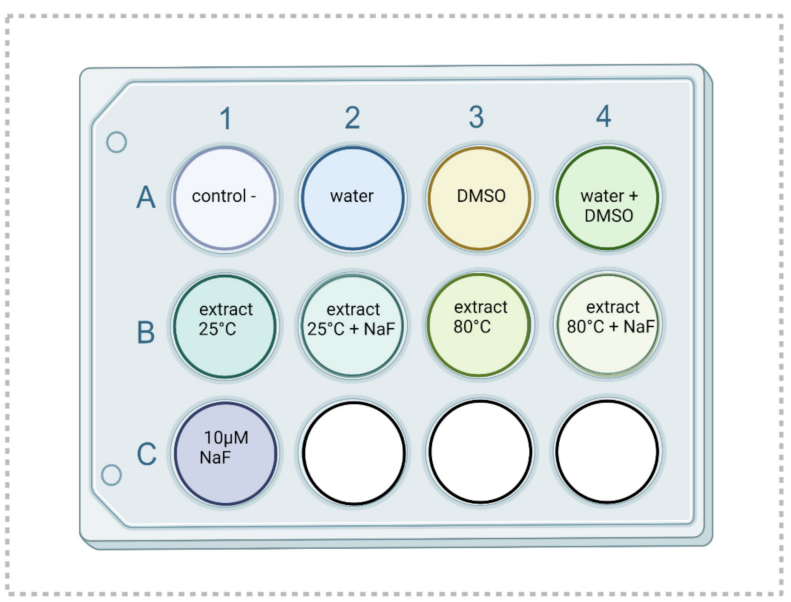

Figure 6. Cell culture with factors incubated with THP-1 line macrophages. The experiment was repeated 5 times. 


\subsection{Imaging of Cytoplasmic ROS Generation}

The production of cytoplasmic ROS was visualised using DCFH-DA (Sigma-Aldrich, Poland). DCFH-DA is a nonpolar dye that is converted into the polar derivative DCFH by cellular esterases. DCFH is non-fluorescent but switches to highly fluorescent DCF when oxidised by intracellular ROS or other peroxides (excitation at $485 \mathrm{~nm}$, emission between 500 and $600 \mathrm{~nm}$ ). DCFH-DA at a concentration of $5 \mu \mathrm{M}$ was added to the cells. After incubation $\left(30 \mathrm{~min}\right.$ at $37^{\circ} \mathrm{C}$ ), the cells were washed with culture medium at room temperature, and the preparations were examined under a confocal microscope (Olympus, SV 1000, Waltham, MA, USA).

\subsection{In Vitro Imaging of Apoptosis}

Cells $\left(1 \times 10^{5}\right.$ cells/well $)$ were incubated with fluoride solutions alone or with an ethanol or water extract on microscope slides according to the aforementioned procedure. After $48 \mathrm{~h}$ of incubation, the cells were rinsed with PBS, suspended in a binding buffer, and stained with $5 \mathrm{ng} / \mathrm{mL}$ Annexin V-FITC and $5 \mathrm{ng} / \mathrm{mL}$ propidium iodide for $5 \mathrm{~min}$ in the dark. Cells that are viable are Annexin V-FITC and PI negative; cells that are in early apoptosis are Annexin V-FITC positive and PI negative (green fluorescence); and cells that are in late apoptosis or already dead (necrosis) are both Annexin V-FITC and PI positive (red fluorescence). A dual-pass FITC/rhodamine filter set was applied. In vitro imaging of apoptosis and necrosis was obtained using confocal microscopy (Olympus, SV 1000, Waltham, MA, USA).

\subsection{Statistical Analysis}

The observations were subjected to a statistical analysis using the Statistica $13.5 \mathrm{soft}$ ware from StatSoft (Poland). In all the experiments, three samples were analyzed, and all the assays were carried out at least in triplicate. The distribution of results was tested with the Shapiro-Wilk test. To evaluate the differences between the studied parameters, the non-parametric Mann-Whitney U-test or the Tukey test was used, depending on the distribution. Correlation analyses were performed using the Pearson test or the Spearman test, depending on the distribution. The statistical significance level was set at $p \leq 0.05$. To control type I errors, the false discovery rate (FDR) approach was used. The calculations were performed using the $\mathrm{p}$. adjust function of the stats package in $\mathrm{R}$ ( $\mathrm{R}$ Foundation for Statistical Computing, Vienna, Austria, https:/ / cran.r-project.org, accessed on 12 June 2021).

\section{Conclusions}

Common goutweed (Aegopodium podagraria L.) has antioxidant properties, which may differ depending on a range of factors. Extraction at $80^{\circ} \mathrm{C}$ and the use of ethanol as a solvent increased the antioxidant capacity of the extract, which may be related to the presence of polyacetylenes, polyphenols, and essential oils. These properties have been confirmed for the first time in cell lines, demonstrating that the extracts unblock antioxidant enzymes and provide protective effects against sodium fluoride toxicity. DMSO (1\%) as a solvent does not have a significant effect on antioxidant capacity determined by FRAP and TFC assay, but when used as a medium in cell cultures, it has proapoptotic activity, disturbing the redox balance. The potential applications of the extracts can be sought in phytotherapy for the support and treatment of conditions involving enhanced oxidative stress, e.g., inflammatory conditions, cardiovascular diseases, neurodegenerative diseases, and even obesity. However, there is a shortage of in-depth research studies presenting the relative content of bioactive compounds in individual parts of the goutweed plant, which shows potential for further research in this scope. In future research, it would be important to consider different, lower extract concentrations and to study other parts of the plant. Another important aspect is the bioavailability and antioxidant properties of the digestive extracts available to the colon, as well as the loss of bioactive compounds during the digestion process. Additionally, it seems necessary to analyse goutweed composition further, including the quantitative and qualitative determination of polyphenolic compounds. 
Author Contributions: Conceptualisation, K.J. and K.J.-M.; methodology K.J., S.C., I.G., A.W.-B.; investigation, K.J., A.Ł., S.C., I.G., A.W.-B.; M.T.; writing—original draft preparation, K.J.; writingreview and editing, K.J.-M.; supervision, K.J.-M., N.C.; project administration, K.J.-M. and K.J.; funding acquisition, N.C. All authors have read and agreed to the published version of the manuscript.

Funding: This research was funded by the Pomeranian Medical University in Szczecin.

Institutional Review Board Statement: Not applicable.

Informed Consent Statement: Not applicable.

Data Availability Statement: Not applicable.

Conflicts of Interest: The authors declare no conflict of interest.

\section{References}

1. Stefanovic, O.; Comic, L.; Stanojevic, D.; Solujic-Sukdolak, S. Antibacterial Activity of Aegopodium podagraria L. Extracts and Interaction Between Extracts and Antibiotics. Turk. J. Biol. 2009, 33, 145-150.

2. Jakubczyk, K.; Kwiatkowski, P.; Sienkiewicz, M.; Janda, K. The content of polyphenols in extract from goutweed (Aegopodium podagraria L.) and their antistaphylococcal activity. Postępy Fitoter. 2018, 19, 3-9.

3. Jakubczyk, K.; Janda, K.; Styburski, D.; Łukomska, A. Goutweed (Aegopodium podagraria L.)—Botanical Characteristics and Prohealthy Properties. Postepy Hig. Med. Dosw. 2020, 74, 28-35. [CrossRef]

4. Christensen, L.P.; Brandt, K. Bioactive Polyacetylenes in Food Plants of the Apiaceae Family: Occurrence, Bioactivity and Analysis. J. Pharm. Biomed. Anal. 2006, 41, 683-693. [CrossRef] [PubMed]

5. Orav, A.; Viitak, A.; Vaher, M. Identification of Bioactive Compounds in the Leaves and Stems of Aegopodium podagraria by Various Analytical Techniques. Procedia Chem. 2010, 2, 152-160. [CrossRef]

6. Young, J.F.; Christensen, L.P.; Theil, P.K.; Oksbjerg, N. The polyacetylenes falcarinol and falcarindiol affect stress responses in myotube cultures in a biphasic manner. Dose Response 2008, 6, 239-251. [CrossRef]

7. Prior, R.M.; Lundgaard, N.H.; Light, M.E.; Stafford, G.I.; van Staden, J.; Jäger, A.K. The Polyacetylene Falcarindiol with COX-1 Activity Isolated from Aegopodium podagraria L. J. Ethnopharmacol. 2007, 113, 176-178. [CrossRef]

8. Castaneda, O.A.; Lee, S.-C.; Ho, C.-T.; Huang, T.-C. Macrophages in Oxidative Stress and Models to Evaluate the Antioxidant Function of Dietary Natural Compounds. J. Food Drug Anal. 2017, 25, 111-118. [CrossRef]

9. Pogozhikh, N.I.; Tovchiga, O.V.; Evlash, V.V.; Stepanova, S.I.; Koyro, O.O. Substantiation of the Rational Drying Conditions for the Herbal Raw Material of Goutweed (Aegopodium podagraria L.) Aerial Part. South Asian Res. J. Nat. Prod. 2018, 1, 1-11.

10. Wróblewska, A.; Janda, K.; Makuch, E.; Walasek, M.; Miądlicki, P.; Jakubczyk, K. Effect of Extraction Method on the Antioxidative Activity of Ground Elder (Aegopodium podagraria L.). Pol. J. Chem. Technol. 2019, 21, 13-18. [CrossRef]

11. Ozkan, G.; Kamiloglu, S.; Ozdal, T.; Boyacioglu, D.; Capanoglu, E. Potential Use of Turkish Medicinal Plants in the Treatment of Various Diseases. Molecules 2016, 21, 257. [CrossRef]

12. Kapetanos, C.; Karioti, A.; Bojović, S.; Marin, P.; Veljić, M.; Skaltsa, H. Chemical and Principal-Component Analyses of the Essential Oils of Apioideae Taxa (Apiaceae) from Central Balkan. Chem. Biodivers. 2008, 5, 101-119. [CrossRef]

13. Szczuko, M.; Zapalowska-Chwyć, M.; Drozd, R. A Low Glycemic Index Decreases Inflammation by Increasing the Concentration of Uric Acid and the Activity of Glutathione Peroxidase (GPx3) in Patients with Polycystic Ovary Syndrome (PCOS). Molecules 2019, 24, 1508. [CrossRef]

14. Kowalska, K. Natural Compounds Involved in Adipose Tissue Mass Control in in Vitro Studies. Postepy Hig. Med. Dosw. 2011, 65, 515-523. [CrossRef] [PubMed]

15. Tomac, I.; Šeruga, M.; Labuda, J. Evaluation of Antioxidant Activity of Chlorogenic Acids and Coffee Extracts by an Electrochemical DNA-Based Biosensor. Food Chem. 2020, 325, 126787. [CrossRef] [PubMed]

16. Jakubczyk, K.; Łukomska, A.; Gutowska, I.; Kochman, J.; Janił, J.; Janda, K. Edible Flowers Extracts as a Source of Bioactive Compounds with Antioxidant Properties-In Vitro Studies. Appl. Sci. 2021, 11, 2120. [CrossRef]

17. Augšpole, I.; Duma, M.; Ozola, B.; Cinkmanis, I. Phenolic Profile of Fresh and Frozen Nettle, Goutweed, Dandelion and Chickweed Leaves. FOODBALT 2017 2017, 36-39. [CrossRef]

18. Zofia, N.-E.; Martyna, Z.-D.; Aleksandra, Z.; Tomasz, B. Comparison of the Antiaging and Protective Properties of Plants from the Apiaceae Family. Oxid. Med. Cell. Longev. 2020, 2020, 5307614. [CrossRef] [PubMed]

19. Petrović, G.M.; Stamenković, J.G.; Kostevski, I.R.; Stojanović, G.S.; Mitić, V.D.; Zlatković, B.K. Chemical Composition of Volatiles; Antimicrobial, Antioxidant and Cholinesterase Inhibitory Activity of Chaerophyllum Aromaticum L. (Apiaceae) Essential Oils and Extracts. Chem. Biodivers. 2017, 14, e1600367. [CrossRef] [PubMed]

20. Esmaeili, H.; Karami, A.; Maggi, F. Essential Oil Composition, Total Phenolic and Flavonoids Contents, and Antioxidant Activity of Oliveria Decumbens Vent. (Apiaceae) at Different Phenological Stages. J. Clean. Prod. 2018, 198, 91-95. [CrossRef]

21. Naima, B.; Abdelkrim, R.; Ouarda, B.; Salah, N.N.; Larbi, B.A.M. Chemical Composition, Antimicrobial, Antioxidant and Anticancer Activities of Essential Oil from Ammodaucus Leucotrichus Cosson \& Durieu (Apiaceae) Growing in South Algeria. Bull. Chem. Soc. Ethiop. 2019, 33, 541-549. [CrossRef] 
22. Aloulou, A.; Hamden, K.; Elloumi, D.; Ali, M.B.; Hargafi, K.; Jaouadi, B.; Ayadi, F.; Elfeki, A.; Ammar, E. Hypoglycemic and Antilipidemic Properties of Kombucha Tea in Alloxan-Induced Diabetic Rats. BMC Complement. Altern. Med. 2012, 12, 63. [CrossRef]

23. Do Nascimento, K.F.; Moreira, F.M.F.; Alencar Santos, J.; Kassuya, C.A.L.; Croda, J.H.R.; Cardoso, C.A.L.; Vieira, M.D.C.; Góis Ruiz, A.L.T.; Ann Foglio, M.; de Carvalho, J.E.; et al. Antioxidant, Anti-Inflammatory, Antiproliferative and Antimycobacterial Activities of the Essential Oil of Psidium Guineense Sw. and Spathulenol. J. Ethnopharmacol. 2018, 210, 351-358. [CrossRef]

24. Paramonov, E.A.; Khalilova, A.Z.; Odinokov, V.N.; Khalilov, L.M. Identification and Biological Activity of Volatile Organic Compounds Isolated from Plants and Insects. III. Chromatography-Mass Spectrometry of Volatile Compounds of Aegopodium podagraria. Chem. Nat. Compd. 2000, 36, 584-586. [CrossRef]

25. Valyova, M.; Tashev, A.; Stoyanov, S.; Yordanova, G. In Vitro Free-Radical Scavenging Activity of Aegopodium podagraria L. and Orlaya Grandiflora (L.) Hoffm. (Apiaceae). J. Chem. Technol. Metall. 2016, 51, 271-274.

26. Flieger, J.; Flieger, M. The [DPPH•/DPPH-H]-HPLC-DAD Method on Tracking the Antioxidant Activity of Pure Antioxidants and Goutweed (Aegopodium podagraria L.) Hydroalcoholic Extracts. Molecules 2020, 25, 6005. [CrossRef]

27. Mao, L.C.; Pan, X.; Que, F.; Fang, X.H. Antioxidant Properties of Water and Ethanol Extracts from Hot Air-Dried and Freeze-Dried Daylily Flowers. Eur. Food Res. Technol. Z. Lebensm.-Unters. -Forsch. A 2006, 222, 236-241. [CrossRef]

28. Spigno, G.; De Faveri, D.M. Antioxidants from Grape Stalks and Marc: Influence of Extraction Procedure on Yield, Purity and Antioxidant Power of the Extracts. J. Food Eng. 2007, 78, 793-801. [CrossRef]

29. Sultana, B.; Anwar, F.; Ashraf, M. Effect of Extraction Solvent/Technique on the Antioxidant Activity of Selected Medicinal Plant Extracts. Molecules 2009, 14, 2167-2180. [CrossRef] [PubMed]

30. Azmir, J.; Zaidul, I.S.M.; Rahman, M.M.; Sharif, K.M.; Mohamed, A.; Sahena, F.; Jahurul, M.H.A.; Ghafoor, K.; Norulaini, N.A.N.; Omar, A.K.M. Techniques for Extraction of Bioactive Compounds from Plant Materials: A Review. J. Food Eng. 2013, 117, 426-436. [CrossRef]

31. Shabir, G.; Anwar, F.; Sultana, B.; Khalid, Z.M.; Afzal, M.; Khan, Q.M.; Ashrafuzzaman, M. Antioxidant and Antimicrobial Attributes and Phenolics of Different Solvent Extracts from Leaves, Flowers and Bark of Gold Mohar [Delonix Regia (Bojer Ex Hook.) Raf.]. Molecules 2011, 16, 7302-7319. [CrossRef]

32. Jakubczyk, K.; Łukomska, A.; Baranowska-Bosiacka, I.; Goschorska, M.; Dec, K.; Wolska, J.; Janda, K.; Piotrowska, K.; Kupnicka, P.; Kupczak, P.; et al. The influence of extracts from the seeds of the common nettle (urtica dioica L.) on the activity of antioxidative enzymes in macrophages incubated with sodium fluoride. Fluoride 2018, 51, 65-76.

33. Barbier, O.; Arreola-Mendoza, L.; Del Razo, L.M. Molecular Mechanisms of Fluoride Toxicity. Chem. Biol. Interact. 2010, 188, 319-333. [CrossRef] [PubMed]

34. Miranda, G.H.N.; Gomes, B.A.Q.; Bittencourt, L.O.; Aragão, W.A.B.; Nogueira, L.S.; Dionizio, A.S.; Buzalaf, M.A.R.; Monteiro, M.C.; Lima, R.R. Chronic Exposure to Sodium Fluoride Triggers Oxidative Biochemistry Misbalance in Mice: Effects on Peripheral Blood Circulation. Oxid. Med. Cell. Longev. 2018, 2018, e8379123. [CrossRef]

35. Gutowska, I.; Baranowska-Bosiacka, I.; Goschorska, M.; Kolasa, A.; Łukomska, A.; Jakubczyk, K.; Dec, K.; Chlubek, D. Fluoride as a Factor Initiating and Potentiating Inflammation in THP1 Differentiated Monocytes/Macrophages. Toxicol. In Vitro 2015, 29, 1661-1668. [CrossRef]

36. Cevallos, A.M.; Herrera, J.; López-Villaseñor, I.; Hernández, R. Differential Effects of Two Widely Used Solvents, DMSO and Ethanol, on the Growth and Recovery of Trypanosoma Cruzi Epimastigotes in Culture. Korean J. Parasitol. 2017, 55, 81-84. [CrossRef] [PubMed]

37. Verheijen, M.; Lienhard, M.; Schrooders, Y.; Clayton, O.; Nudischer, R.; Boerno, S.; Timmermann, B.; Selevsek, N.; Schlapbach, R.; Gmuender, H.; et al. DMSO Induces Drastic Changes in Human Cellular Processes and Epigenetic Landscape in Vitro. Sci. Rep. 2019, 9, 4641. [CrossRef]

38. Tunçer, S.; Gurbanov, R.; Sheraj, I.; Solel, E.; Esenturk, O.; Banerjee, S. Low Dose Dimethyl Sulfoxide Driven Gross Molecular Changes Have the Potential to Interfere with Various Cellular Processes. Sci. Rep. 2018, 8, 14828. [CrossRef] [PubMed]

39. Galvao, J.; Davis, B.; Tilley, M.; Normando, E.; Duchen, M.R.; Cordeiro, M.F. Unexpected Low-Dose Toxicity of the Universal Solvent DMSO. FASEB J. Off. Publ. Fed. Am. Soc. Exp. Biol. 2014, 28, 1317-1330. [CrossRef]

40. Mannan, A.; Liu, C.; Arsenault, P.R.; Towler, M.J.; Vail, D.R.; Lorence, A.; Weathers, P.J. DMSO Triggers the Generation of ROS Leading to an Increase in Artemisinin and Dihydroartemisinic Acid in Artemisia Annua Shoot Cultures. Plant Cell Rep. 2010, 29, 143-152. [CrossRef]

41. Pekkarinen, S.S.; Stöckmann, H.; Schwarz, K.; Heinonen, I.M.; Hopia, A.I. Antioxidant Activity and Partitioning of Phenolic Acids in Bulk and Emulsified Methyl Linoleate. J. Agric. Food Chem. 1999, 47, 3036-3043. [CrossRef]

42. Benzie, I.F.; Strain, J.J. The Ferric Reducing Ability of Plasma (FRAP) as a Measure of Antioxidant Power: The FRAP Assay. Anal. Biochem. 1996, 239, 70-76. [CrossRef]

43. Benzi, F.; Szeto, Y. Total Antioxidant Capacity of Teas by the Ferric Reducing/Antioxidant Power Assay. J. Agric. Food Chem. 1999, 47, 633-636. Available online: https://pubs.acs.org/doi/10.1021/jf9807768 (accessed on 5 July 2019). [CrossRef]

44. Singleton, V.L.; Rossi, J.A. Colorimetry of Total Phenolics with Phosphomolybdic-Phosphotungstic Acid Reagents. Am. J. Enol. Vitic. 1965, 16, 144-158. 